\title{
The Cyprinodon variegatus genome reveals gene expression changes underlying differences in skull morphology among closely related species
}

\author{
Ezra S. Lencer ${ }^{1 *}$ (D), Wesley C. Warren ${ }^{2}$, Richard Harrison ${ }^{1 \wedge}$ and Amy R. McCune ${ }^{1}$
}

\begin{abstract}
Background: Understanding the genetic and developmental origins of phenotypic novelty is central to the study of biological diversity. In this study we identify modifications to the expression of genes at four developmental stages that may underlie jaw morphological differences among three closely related species of pupfish (genus Cyprinodon) from San Salvador Island, Bahamas. Pupfishes on San Salvador Island are trophically differentiated and include two endemic species that have evolved jaw morphologies unlike that of any other species in the genus Cyprinodon.
\end{abstract}

Results: We find that gene expression differs significantly across recently diverged species of pupfish. Genes such as Bmp4 and calmodulin, previously implicated in jaw diversification in African cichlid fishes and Galapagos finches, were not found to be differentially expressed among species of pupfish. Instead we find multiple growth factors and cytokine/chemokine genes to be differentially expressed among these pupfish taxa. These include both genes and pathways known to affect craniofacial development, such as Wnt signaling, as well as novel genes and pathways not previously implicated in craniofacial development. These data highlight both shared and potentially unique sources of jaw diversity in pupfish and those identified in other evolutionary model systems such as Galapagos finches and African cichlids.

Conclusions: We identify modifications to the expression of genes involved in Wnt signaling, Igf signaling, and the inflammation response as promising avenues for future research. Our project provides insight into the magnitude of gene expression changes contributing to the evolution of morphological novelties, such as jaw structure, in recently diverged pupfish species.

Keywords: Craniofacial, Transcriptomics, Development, Genome, Skull, Pupfish, Evolution

\section{Background}

A central goal of evolutionary biology is to understand the origins of phenotypic diversity. Critical to this task is elucidating how new phenotypic variation is produced during the early stages of species diversification. It is now widely appreciated that modified gene expression often underlies the origins of new variation at both deep and shallow phylogenetic scales [1-5]. Studies have

\footnotetext{
* Correspondence: El468@cornell.edu

'Deceased

'Department of Ecology and Evolutionary Biology, Cornell University, Ithaca, NY 14850, USA

Full list of author information is available at the end of the article
}

largely focused on identifying how the expression of conserved genes are modified in different taxa. However, until recently, a challenge has been to identify additional sets of genes that may contribute to variation in phenotypes of interest. This is especially important for complex traits where phenotypic variation available to selection may be produced through interactions of multiple genes as well as environmental factors.

Skull morphology is an ecologically critical complex trait that varies widely across vertebrate taxa, and fishes offer a great diversity of skull and jaw morphology that are both functionally important and relatively accessible 
to study [6-10]. Model organisms such as zebrafish or medaka lack the phenotypic diversity of interest, but nonmodel organisms like cichlid fishes or pupfishes display this diversity and are also easy to rear in the lab [9, 11-13]. From a developmental perspective, specification and differentiation of skeletal head elements depends on complex interactions between the brain, facial epithelium, neural crest derived mesenchyme, and head endoderm during embryonic development [14-17]. Given the complexity of skull development, it is often thought that the enormous diversity of vertebrate skull forms could be produced through tweaking a conserved skull developmental program in different ways $[10,11,18,19]$. Our understanding of how skull morphological diversity is produced in wild taxa is still largely limited to work on Galapagos finches and African cichlids. Amazingly, early work in both finches and cichlids showed that differences in jaw morphology is associated with altered expression of the same genes, Bmp4 and calmodulin [11, 20-22]. However, sources of jaw phenotypic variation can be unique. Ongoing work in Caribbean bullfinches, close relatives of Galapagos finches, indicated that modification to the expression of different genes underlie jaw diversity among these taxa [19]. Other mechanisms, including roles for hedgehog signaling and Wnt signaling, have been proposed in different taxa [16, 23-29]. Thus a major next step is to both understand how and in what ways the genetic sources of phenotypic diversity in skull form vary across clades, as well as to identify additional genes and potential regulatory interactions that link gene expression to alterations in cell behavior that ultimately produce morphological variation.

Here, we use RNA-seq to identify a set of genes that may contribute to striking differences in jaw morphology among three ecologically differentiated pupfish species (genus Cyprinodon) from San Salvador Island Bahamas (Fig. 1). One of these island species is a population of the widespread $C$. variegatus, believed to have the pleisiomorphic jaw morphology for the group, while the other two species are endemic to San Salvador Island and exhibit unique jaw morphologies among the $\sim 50$ species of Cyprinodon [12, 13, 30, 31].

Our previous research indicates that species differ in the relative growth rates of individual bones of the skull during larval and juvenile growth [13]. Modifications to growth rates have long been proposed as a mechanism by which morphological diversity may be produced $[32,33]$, however, there is little known about how growth is modified at a molecular level, especially among wild taxa.

In pupfishes, altered growth of jaw bones might be due to altered gene expression during embryonic development as occurs in cichlids and finches, or it could be due largely to altered morphogenetic growth processes during post-hatching development. To investigate, we characterize gene expression among species at four developmental stages corresponding to major periods of skull differentiation and growth during both embryonic and post-hatching life stages. We sequenced and assembled the genome of the pupfish, C. variegatus, to serve as our reference in these studies. Our data identify a number of transcription factors, growth factors, and bone cell stimulatory molecules differentially expressed at embryonic and larval periods that may be related to differences in skull morphology among species of San Salvador pupfishes. Here we report on the Cyprinodon genome and the results from the RNA-seq study, revealing potential sources of skull morphological variation in pupfishes.

\section{Methods}

Study system

San Salvador pupfish species differ dramatically in cranial morphology and trophic ecology [12, 13]. One species, considered a population of the widespread C. variegatus, is an omnivore that exhibits the likely ancestral morphology $[12,34,35]$. The two other species on the island are endemic and exhibit unique jaw morphologies relative to all other Cyprinodon [13, 30, 36]. A scale-biter, C. desquamator, uses its enlarged upturned jaws to feed on the scales and body slime of other pupfishes (Fig. 1). The durophage, C. brontotheroides, feeds on hard-shelled prey such as snails, and has small robust jaws that are nested underneath maxilla and nasal bone extensions (Fig. 1). All three species occur in sympatry in a number of inland saltwater lakes on San Salvador Island. These inland lakes are not connected with the ocean. A population of $C$. variegatus also occurs in a mangrove estuary on the southern end of the island, and this hardy species is widespread on the North Atlantic coast from Massachusetts to Florida [37, 38]. Previous phylogenetic studies have suggested the mangrove estuarine population of $C$. variegatus and the inland lacustrine populations are genetically distinct despite their morphological similarity and taxonomic identity [31, 39]. For simplicity, in this paper, we will use informal names for these taxa descriptive by trophic ecology and/or habitat. We thus refer to $C$. desquamator as the scale-biter and C. brontotheroides as the durophage. Sympatric with these two species are the inland $C$. variegatus or the "inland omnivore." The marine estuarine population of C. variegatus is simply the "marine omnivore."

Morphological differences among species of pupfishes arise from differential growth rates of individual bones [13]. Oral jaw bones in the scale-biter grow at significantly faster rates during post-hatching growth than either of the other two species. In contrast, oral jaw bones of the durophage increase in size at significantly slower rates than either of the other two species during this same period. Changes to the relative growth rates of 


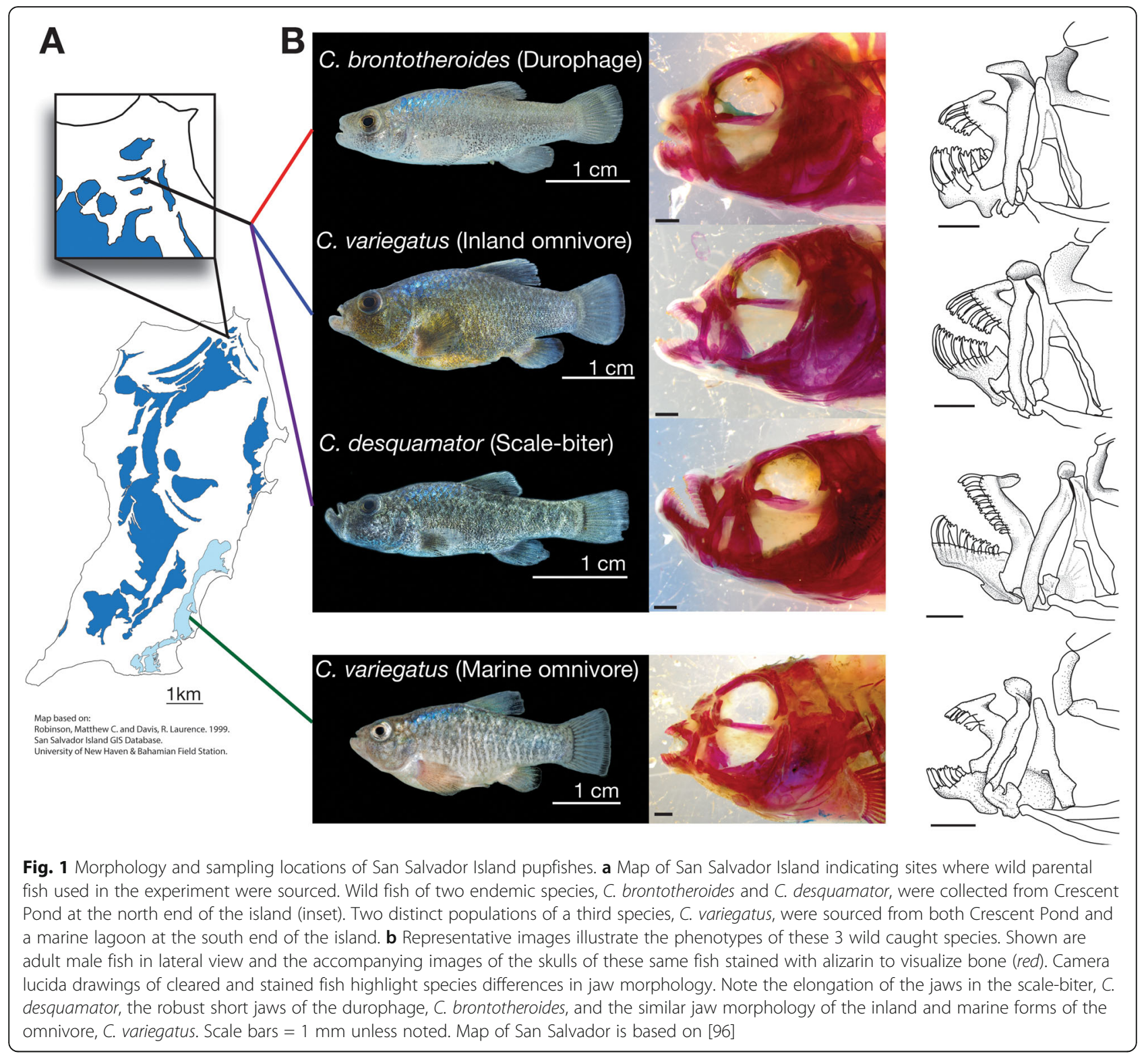

these individual jaw bones affect not only the adult size and shape of the bones, but also the overall skull shape, through the relative placement and interconnections of individual bones. For example the relatively small robust jaws of the durophage means that the jaws are positioned underneath the maxilla and nasal bones, giving the skull a very different appearance than in other species (Fig. 1). Measurable morphological differences emerge through juvenile growth, and by 17 days post fertilization (dpf), juvenile fish of each species have measurable differences in relative jaw size. However, these differences in growth rates during post-hatching stages could arise from either embryonic specification of jaw structures prior to hatching or from modifications solely to post-hatching growth.

\section{Genome sequencing and annotation}

We sequenced and annotated the genome of C. variegatus. DNA used for sequencing the $C$. variegatus genome was obtained from a tissue sample of a single female identified as N-32, collected in 2010 at Navarre, FL, USA and provided to us by Diane Nacci at the EPA. Sequences of $100 \mathrm{bp}$ length were generated on an Illumina HiSeq2500 instrument. Sequences were assembled according to default parameter recommendations provided in the AllPaths-LG assembler [40]. This model requires $\sim 40 \times$ sequence coverage from each of overlapping (200 bp fragment size) and $3 \mathrm{~kb}$ Illumina paired-end (PE) reads and $10 \times$ of $8 \mathrm{~kb}$ PE Illumina reads. In the C_variegatus-1.0 assembly (NCBI) we removed contaminating contigs, trimmed vector sequence in the form of 
X's, and ambiguous bases in the form of N's in the sequence data. All scaffolds (singletons) and contigs within scaffolds that were $200 \mathrm{bp}$ and less in length were removed from the assembly.

Gene annotation of the $C$. variegatus reference genome (C._variegatus-1.0) was completed according to previously established NCBI procedures (https://www.ncbi.nlm.nih.gov/genome/annotation_euk/process/).

\section{Animal husbandry and breeding for RNA-seq study}

Wild caught Cyprinodon pupfishes from San Salvador Island, Bahamas, were maintained at Cornell University in 5 parts per thousand (ppt) brackish water at a constant temperature of $27{ }^{\circ} \mathrm{C}$ and a $14 \mathrm{~h}$ light/10 h dark schedule. Male-female pairs of wild caught fish were allowed to breed undisturbed for $1 \mathrm{~h}$, after which clutches of eggs were collected and reared in petri-dishes with daily water changes. Larvae were transferred to 3 gal zebrafish rack tanks after hatching, which typically occurred between 7 to 8 days post fertilization (dpf). Hatched fish were fed daily live brine shrimp ad libitum beginning on $8 \mathrm{dpf}$, and water was changed every other day. All wild collections, animal husbandry, and procedures were approved by Cornell IACUC, protocol number 2011-0045 to ESL and ARM. Field research was conducted under Bahamas Environment, Science \& Technology permit issued on November 10, 2012 and Export Permit 23/2013 issued on February 4, 2013.

\section{Sampling and dissections for RNA-seq}

Full-sib clutches were sampled at $48 \mathrm{~h}$ post fertilization (hpf) corresponding to medaka embryonic stage 26-27 (Cyprinodon stage 26 from Lencer in prep.; head development similar to approx. Early Pharyngula Period of zebrafish) [41], $96 \mathrm{hpf}$ corresponding to medaka embryonic stage 34-35 (Cyprinodon stage 30 from Lencer in prep.; head development similar to approx. Early Hatching Period of zebrafish) [41], $8 \mathrm{dpf}$ (hatching larvae), and $15 \mathrm{dpf}$ (juvenile fish). The stages sampled here cover a wide span of developmental time during which cell types and organs are differentiating. To account for this and to make samples as comparable across stages as possible we performed slightly different dissections at each stage. For example, we excluded eye and brain tissue from latter stages in order to remove these transcriptionally active organs. Dissections were performed similarly for all species, and we focus our comparisons among different taxa sampled at the same stage (see below). Fish were euthanized with an overdose of MS-222. For embryonic stages, head tissue was dissected away from the body and placed in RNAlater (Thermo Fisher Scientific) for long term storage. The $48 \mathrm{hpf}$ samples were dissected by removing the body away from the yolk and heart using forceps, and then by removing the entire head just posterior to the developing otic capsule. For 96 hpf fish, the body was dissected from the yolk and heart and the eyes were removed using forceps. The entire head of $96 \mathrm{hpf}$ fish was then removed from the body just anterior to the pectoral fin buds.

Larval and juvenile fish (8 dpf and $15 \mathrm{dpf}$ ) were stored in RNAlater immediately after euthanizing, and dissections were conducted in RNAlater at a subsequent date. The eyes and brain of larval fish were gently removed with forceps. The head was then removed from the body anterior to the pectoral girdle by gently pulling the heart posteriorly away from the head to separate the pharyngeal arches from the yolk, and by pulling gently along the pectoral girdle anterior edge to fully separate the head.

\section{RNA-seq library preparation}

Four biological replicates were included for each species at each stage, where each biological replicate was produced from pools of the dissected heads of 10 full siblings sampled at the same stage. We used a different parental pair for each biological replicate of a given species at a given stage (total number of parental pairs across all stages are: durophage $=5$, scale-biter $=6$; inland omnivore $=4$, marine omnivore $=5$ ).

Total RNA was extracted using the TRIzol Plus RNA Purification Kit (Thermo Fisher Scientific) and checked for quality by running on an agarose gel. A subset of samples were quality checked for RNA integrity using an Agilent bioanalyzer.

Total RNA was treated with TURBO DNase (Thermo Fisher Scientific) followed by mRNA purification by processing through the NEBNext Poly(A) mRNA Magnetic Isolation Module twice (NEB). Isolated mRNA was used as library preparation material for Illumina sequencing using the NEBNext Ultra directional kit and NEBNext Multiplex Oligos for Illumina (NEB) as follows: fragmentation time was reduced to $4 \mathrm{~min}$ at $96{ }^{\circ} \mathrm{C}$ based on empirical results, final libraries were amplified using 15 PCR cycles, and final libraries post PCR were size selected using a two step AMPure bead isolation procedure $(0.65 \times /$ $0.15 \times$, NEB manual). All libraries were quality checked by running on a $1.2 \%$ agarose gel. A subset of libraries were size checked on a Agilent bioanalyzer. All libraries showed a single peak of approximately $360-380 \mathrm{bp}$, indicating an insert size of around $240-260 \mathrm{bp}$.

Eight individually barcoded libraries (each lane had 2 libraries of a single species from each of the 4 taxa) were pooled and sequenced on a single Illumina lane (single end $150 \mathrm{bp}$ sequencing Illumina HiSeq2500) for a total of 8 lanes and 64 samples (4 biological replicates for each of 4 taxa at each of 4 stages). A machine 
malfunction during the flow cell annealing step led to sequence quality dropping off after $60-100 \mathrm{bp}$ in our final sequences. This machine was fixed and all libraries were re-sequenced (again single end 150 bp sequencing Illumina HiSeq2500). This second sequencing reaction produced $150 \mathrm{bp}$ reads of high quality throughout the majority of reads. Running analyses separately on each sequencing run indicated that there were no major differences in results between the first and second sequencing runs, so reads from both sequencing runs were pooled and used for downstream analyses.

\section{Bioinformatic analysis of RNA-seq data}

Reads were trimmed of adapter sequences and low quality regions using Trimmomatic [42], and all reads trimmed to a size shorter than 36 bp were discarded. Reads were aligned to the Cyprinodon variegatus genome (C. cyprinodon-1.0) using STAR aligner (version 2.5.1b), mapping only to annotated splicing junctions with a maximum mismatch of $3 \mathrm{bp}$ per read [43]. Read counts per gene were generated using STAR quant mode, which is identical to the HTSeq union method of counting reads (personal observation; STAR manual). We observed no differences in mapping rates across taxa (Additional file 1: Table S1).

We built generalized linear models (GLM) in edgeR to analyze gene expression differences among pupfish taxa at each stage. Mitochondrial genes and genes annotated as pseudogenes were removed prior to analysis. We filtered low expressed genes to include only genes expressed at a level of at least 1 count per million (cpm; approx. 15-20 reads) in half of the samples of a given stage across all taxa, or at a level of $2 \mathrm{cpm}$ in a quarter of the samples of a given stage across all taxa. With this filtering criteria, genes expressed in only a single taxon were maintained in our dataset. Changing the stringency of our filtering criteria has negligible consequences on our analyses and does not affect our major conclusions.

\section{Enrichment analyses}

We identified 1-to-1 pupfish orthologs as the reciprocal best blast to zebrafish (NCBI, GRCz10). Gene names used in this paper correspond to ortholog assignments to zebrafish using this method. In cases where pupfish genes could not be assigned to a zebrafish ortholog we use the annotated pupfish gene identifier. Inspection of these genes indicated that many were paralogs of known genes. Teleosts, including pupfish and zebrafish, have undergone a whole genome duplication and we suspect that some paralogous gene copies could not be assigned as 1-to-1 orthologs using a reciprocal best blast approach. Orthology tables obtained from Zebrafish Model Organism (ZFIN) and Mouse Genome Informatics
(MGI) databases were used to identify pupfish orthology relationships to mice and human genes.

We performed gene set enrichment analysis (GSEA, version 2-2.24) as implemented in the Broad Institute's java command line program [44]. Genes were preranked by either the log2-fold difference in expression values based on edgeR results, or in a separate series of analyses by each gene's loadings on the first 3-4 principal component axes (see results). We tested for enrichment of gene sets in the GSEA hallmark sets v6 (50 gene sets) and the canonical pathways set v6 (1329 gene sets) using the classic scoring scheme and conducted 1000 permutations to determine significance. Genes without human identifiers were excluded from the analysis. Our results are similar when ranking genes by the mean $\log 2$ fold difference across all pairwise comparisons to a focal taxon, or by ranking genes based on significance.

For overrepresentation analysis, we used Blast2GO software to extract gene ontology (GO) annotations for genes based on BLAST similarity to UniProtKB/Swiss-Prot protein sequences. The package GOstats, as implemented in $\mathrm{R}$, was used to perform enrichment analyses [45]. We additionally used DAVID and WebGestalt software to perform enrichment analyses using either the zebrafish reciprocal best blast gene ids (DAVID) or Human gene symbols (WebGestalt) as gene inputs [46, 47]. Results from these analyses were used heuristically to manually curate genes into functional categories $[47,48]$.

\section{Phylogenetic analysis}

SNPs were called from RNA-seq reads using the GATK haplotype caller following the recommended "Best Practices" for RNA-seq data. Reads were mapped to the $C$. variegatus genome using STAR aligner in a two pass method that uses the predicted splicing junctions from the first pass as the annotated splicing junctions for the second mapping pass. Duplicate reads were marked using Picard Tools, spiced reads were split using the GATK splitNcigar tool, and SNPs were called using the GATK haplotype caller including all libraries and excluding soft clipped bases. SNPs were filtered using the GATK Variant Filtration Tool (Fischer Strand >30, > 3 SNPs per 35 bp window, Quality by depth $<2$ ). We used vcftools to further filter all indels, SNPs with a depth less than 10, and any missing data. We used bcftools to extract the consensus sequence for each replicate, and used bedtools to extract only those regions that had a coverage of at least 10 reads at all bases and a contiguous length of between $50 \mathrm{bp}$ to $1 \mathrm{~kb}$. These regions were concatenated to produce $\sim 36 \mathrm{Mb}$ of both variant and invariant exonic sequence (Fig. 2a,b).

We used RAxML to infer phylogenetic relationships among species. Tips in the phylogeny refer to parental 

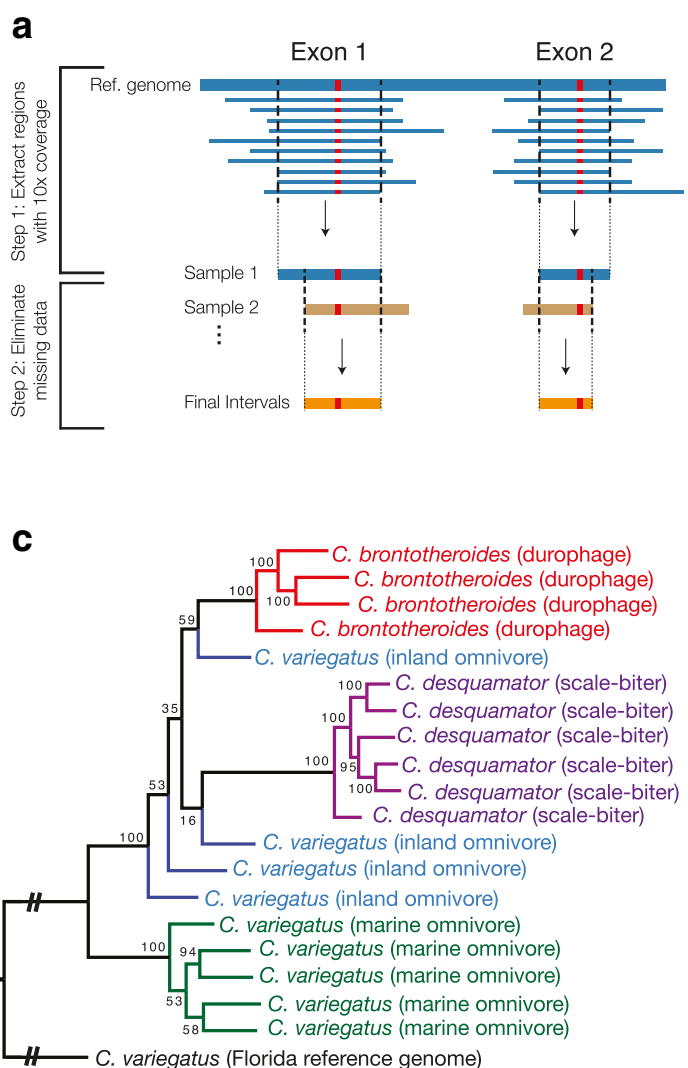

b

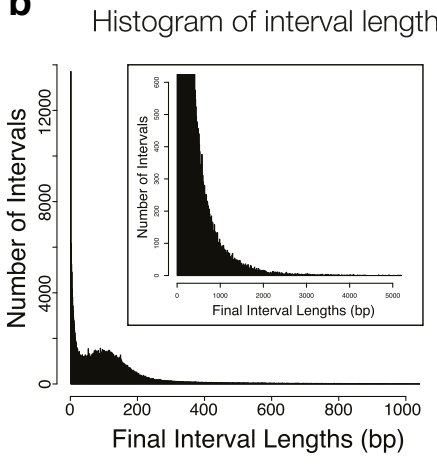

d

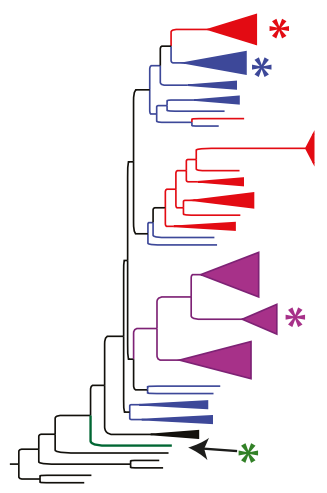

Fig. 2 Phylogenetic relationships among species of pupfish from San Salvador Island. a Overview of bioinformatic methods to generate sequence data for phylogenetic analysis. Consensus genome sequences were generated for each parental pair by substituting SNP (red bars) allele assignments. Genomic intervals for use in phylogenetic analysis were selected based on contiguous regions that had a minimum coverage of 10 reads at every nucleotide position. We then further selected intervals across all parental pairs such that there was no missing data in our dataset. $\mathbf{b}$ The length distribution of genomic intervals used for phylogenetic reconstruction (from a). Inset shows intervals exceeding 1 kb in length. Many intervals are less than $10 \mathrm{bp}$ long and some intervals are over $1 \mathrm{~kb}$ in length. We restricted our final interval set to regions that were longer than $50 \mathrm{bp}$ and less than $1 \mathrm{~kb}$. c. A maximum likelihood tree built from expressed exonic sequence data produced from the current study, and d. a maximum likelihood tree built from RAD-seq data, reproduced here from Martin and Feinstein [31, 50]. Note the overall congruence in the inferred phylogenetic relationships among taxa from both studies. In particular, both studies find a monophyletic San Salvador Island clade and that the marine omnivore population diverges prior to the speciation of endemic San Salvador taxa. Stars in $\mathbf{d}$. indicate samples from the same populations as those of the current study

pairs used in our experiment. A single durophage pair was excluded because we only had data for one stage. Sequence alignments were divided into 14 partitions using the $\mathrm{k}$ means algorithm as implemented in PartitionFinder [49]. We applied a GTR+ gamma model, and conducted 500 bootstraps to estimate node support. We found similar tree topologies when running our data as a single partition and when applying a GTRCAT model in RAxML indicating that our phylogenetic estimation from our data is robust to different models (Additional file 2: Figure S1).

\section{Results}

Genome assembly and gene annotation

Total assembled sequence coverage of Illumina sequences for genome assembly were $\sim 81 \times$ using a genome size estimate of $1.0 \mathrm{~Gb}$. The C._variegatus-1.0 assembly
(GCA_000732505.1 accession number) comprises a total of 9259 scaffolds with an N50 scaffold length over $835 \mathrm{~Kb}$ (N50 contig length was $20.8 \mathrm{~Kb}$ ). The total assembled size is $899 \mathrm{Mb}$ excluding gaps.

Gene annotation of the C._variegatus-1.0 reference utilizing the NCBI pipeline generated 23,373 proteincoding genes and 1010 non-coding genes. A full report of this predicted gene set is given at https:// www.ncbi.nlm.nih.gov/genome/annotation_euk/Cyprinodon_variegatus $/ 100 /$.

Phylogenetic relationships among San Salvador pupfishes Phylogenetic relationships among species of pupfishes were determined using SNPs from the RNA-seq dataset called via the GATK pipeline and alignment of reads to the C._variegatus-1.0 reference. Of 267,263 variable sites, 202,778 were variable among the Bahamian taxa. The 
other 64,485 sites were only variable between the San Salvador Island samples in our study and the reference genome sequence reflecting the outgroup status of the Florida population from which our reference is derived. From these data we concatenated $\sim 36 \mathrm{Mb}$ of both variant and invariant expressed exonic sequence data that was used for phylogenetic inference (Fig. 2a,b).

A maximum likelihood (ML) tree estimated from our concatenated dataset using RAxML placed the marine omnivore population as an outgroup to a monophyletic San Salvador clade (Fig. 2c). This agrees with previous studies based on anonymous genomic loci identified from a RAD-seq dataset (Fig. 2d) [31, 39, 50]. Thus, despite the marine omnivore and inland omnivore being morphologically similar and sharing taxonomic identity, mounting evidence indicates that the marine omnivore is an outgroup to an endemic San Salvador clade, which includes all three trophic forms.

Among the three inland trophic forms of pupfish (scale-biter, durophage, and inland omnivore), we resolved the durophage and scale-biter as monophyletic in concordance with previous studies [31,39]. However the inland omnivore is paraphyletic in our ML tree, and bootstrap support for nodes resolving inland omnivore samples tend to be low. The durophage and scale biter comprise less than $10 \%$ of all fish in any given lake (personal observation) $[12,35]$, and demographic processes may partially account for why we resolve these taxa as monophyletic in our tree. Paraphyly of the inland omnivore may reflect both incomplete lineage sorting and ongoing introgression among inland taxa $[31,39]$, or simply that the durophage and scale biter were derived from different populations of the inland omnivore. Low bootstrap support at inland omnivore nodes may also suggest the presence of a hard polytomy at the root of the San Salvador Island clade.

\section{Gene expression divergence among Taxa}

Using RNA-seq, we measured gene expression in the heads of each of the four taxa at the following four developmental stages: (1) $48 \mathrm{~h}$ post fertilization (hpf) analogous to the zebrafish pharyngula period, (2) $96 \mathrm{hpf}$ corresponding to an embryonic period when jaw and neurocranial cartilages are forming, (3) 8 days post fertilization (dpf) corresponding to larval hatching when jaw elements are similar between species, and (4) $15 \mathrm{dpf}$ during a period of juvenile growth when measurable differences in jaw size among species emerge as a consequence of differential growth of individual bony elements (Fig. 3a) [13].

Sequencing produced 2.7 billion reads total after filtering (24.3-54.4 million reads per sample). Mapping rates to the $C$. variegatus genome using STAR aligner exceeded $90 \%$ of reads being uniquely mapped for all samples, and we observed no differences in mapping rates among taxa (Additional file 1: Table S1).

Gene expression varied dramatically across developmental stage owing to true differences in tissue development and our slightly different method of dissections at different stages in an attempt to make the tissue samples as comparable as possible (Additional file 3: Figure S2). Within a stage, as expected, expression levels among libraries derived from all four taxa were highly correlated (Pearson's $r>0.9$ ). Because our primary interest is to understand differences among taxa, we restrict our subsequent analyses of differential expression to comparisons among taxa at the same developmental stage.

Gene expression patterns clearly show separation by taxon along the first 3 principal component axes (PC) for all stages (Fig. 3b; Additional file 4: Figure S3). Nearly half of the total variance in gene expression levels among samples at each stage is attributable to differences among taxa. Inland omnivore samples grouped at all four stages with the durophage samples rather than with the taxonomically and morphologically similar marine omnivore samples. At each stage, a single PC axis separates the marine omnivore population from all three inland San Salvador taxa mirroring the inferred phylogenetic relationships from our ML tree. Thus morphological similarity and gene expression divergence at a transcriptomic scale appear to be decoupled. This pattern would fit a model where either only slight modifications and/or modifications to the expression of only a small proportion of genes contribute to morphological differentiation. This pattern may also reflect ongoing introgression among the inland omnivore and the durophage taxa [31,39], as well as the accumulation of gene expression differences with time since common ancestry.

\section{Gene set enrichment suggests modifications to conserved cellular processes}

We used GSEA to test for enrichment of conserved cellular processes among the genes differentially expressed among taxa. Our conclusions are largely congruent across analyses conducted on the hallmark collection and canonical pathways collection, and so we confine our discussion to results from enrichment of hallmark gene sets and direct interested readers to supplementary tables for more detailed results of canonical pathways (Additional file 5: Table S2, Additional file 6: Table S3, Additional file 7: Table S4, Additional file 8: Table S5, Additional file 9: Table S6 and Additional file 10: Table S7).

We first tested for enrichment of conserved cellular processes along each of the $\mathrm{PC}$ axes at each stage by ranking genes based on each gene's loadings on a PC axis (Table 1; Additional file 5: Table S2 and Additional file 6: Table S3). As an example, PC1 at $48 \mathrm{hpf}$ largely 


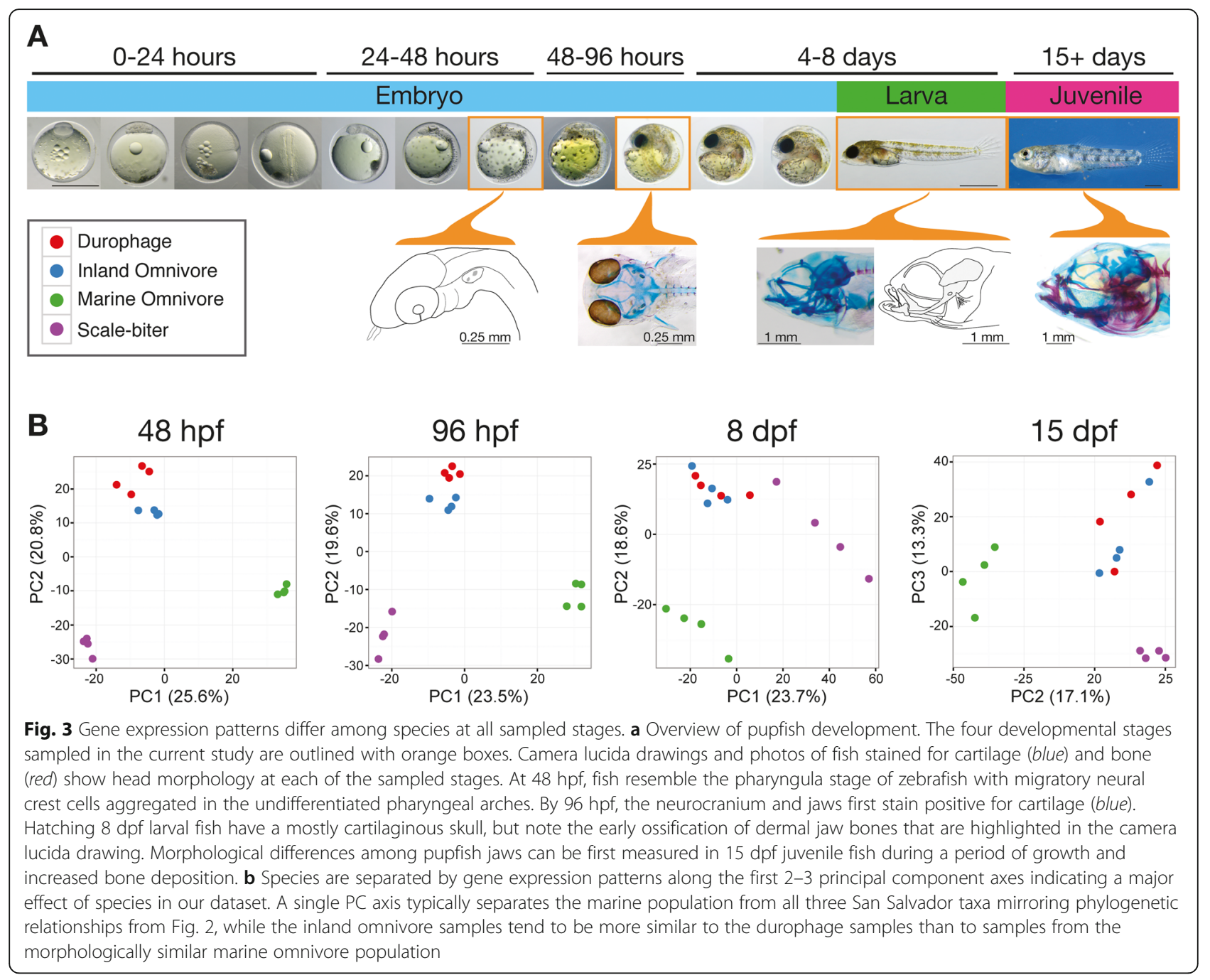

distinguishes the marine omnivore samples from all three of the inland taxa (Fig. 3b). Genes with positive loadings on this axis were enriched for cell cycle related processes such as E2F Targets and Myc Targets, while genes with negative loadings on this axis were enriched for genes involved in the epithelial to mesenchymal transition and KRAS signaling (Table 1; Additional file 5: Table S2). The first several PC axes that distinguish taxa at each stage (see Fig. 3b; Additional file 4: Figure S3) show repeated evidence for enrichment of genes related to cell cycle control, myogenesis, protein secretion, metabolism, the estrogen response, the inflammation response, and genes involved in the epithelial to mesenchymal transition. We observed enrichment for a number of signaling processes including TNF alpha/NF-kB, Interferon alpha and gamma responses, IL-6/Jak/Stat signaling, KRAS signaling, Myc signaling, and to a lesser extent Wnt, Tgf-B, and hedgehog signaling. Results from GSEA enrichment analysis of canonical pathways were congruent with results based on the hallmark gene sets (Additional file 6: Table S3).

We next used GSEA to test for enrichment of gene sets in the genes over- or underexpressed in either the durophage or the scale-biter at each developmental stage relative to all other taxa by ranking genes based on the estimated $\log 2$ fold difference. Perhaps not surprisingly we found many of the same gene sets enriched when ranking genes by over- or underexpression as we found enriched when ranking genes by loadings onto the PC axes that distinguish samples by taxa (Tables 2 and 3; Additional file 7: Table S4, Additional file 8: Table S5, Additional file 9: Table S6 and Additional file 10: Table S7). We observed enrichment at every stage for gene sets suggesting modification to cell cycle regulation. In particular, genes underexpressed in the scale-biter at $48 \mathrm{hpf}$ and $8 \mathrm{dpf}$ are greatly enriched for functions related to cell cycle regulation and progression as further evidenced by enrichment of canonical pathways (Additional file 9: Table S6). We found 
Table 1 Enrichment (GSEA) of top Hallmark Gene Sets along principal component axes for each stage

\begin{tabular}{|c|c|c|c|c|c|c|c|}
\hline \multirow{2}{*}{\multicolumn{2}{|c|}{$\begin{array}{l}48 \text { Hours Post Fertilization } \\
\text { PC1 } \\
\text { (Separates Marine From Inland } \\
\text { Taxa) }\end{array}$}} & \multicolumn{2}{|l|}{96 Hours Post Fertilization } & \multicolumn{2}{|l|}{8 Days Post Fertilization } & \multicolumn{2}{|l|}{15 Days Post Fertilization } \\
\hline & & \multicolumn{2}{|c|}{$\begin{array}{l}\text { PC1 } \\
\text { (Separates Marine From Inland } \\
\text { Taxa) }\end{array}$} & \multicolumn{2}{|c|}{$\begin{array}{l}\text { PC1 } \\
\text { (Separates Scale-Biter From Taxa) }\end{array}$} & \multicolumn{2}{|c|}{$\begin{array}{l}\text { PC2 } \\
\text { (Separates Marine From Inland } \\
\text { Taxa) }\end{array}$} \\
\hline Name & NES & Name & NES & Name & NES & Name & NES \\
\hline \multicolumn{2}{|l|}{ Positive Loadings: } & \multicolumn{2}{|l|}{ Positive Loadings: } & \multicolumn{2}{|l|}{ Positive Loadings: } & \multicolumn{2}{|l|}{ Positive Loadings: } \\
\hline E2F Targets & 2.84 & Interferon Gamma Resp. & 2.81 & Uv Response Dn & 2.53 & Myogenesis & 2.99 \\
\hline G2M Checkpoint & 2.73 & Interferon Alpha Response & 2.14 & Il2 Stat5 Signaling & 2.36 & II2 Stat5 Signaling & 2.88 \\
\hline Mitotic Spindle & 2.17 & Xenobiotic Metabolism & 2.14 & Tnfa Signaling Via Nfkb & 2.35 & Uv Response Dn & 2.86 \\
\hline Protein Secretion & 2.14 & Bile Acid Metabolism & 1.98 & Kras Signaling Dn & 2.29 & Inflammatory Response & 2.64 \\
\hline Myc Targets V1 & 1.86 & Protein Secretion & 1.82 & Allograft Rejection & 2.18 & Allograft Rejection & 2.57 \\
\hline Dna Repair & 1.74 & Oxidative Phosphorylation & 1.80 & P53 Pathway & 2.10 & Kras Signaling Dn & 2.54 \\
\hline Xenobiotic Metabolism & 1.54 & E2F Targets & 1.73 & Inflammatory Response & 1.99 & Hedgehog Signaling & 2.05 \\
\hline $\begin{array}{l}\text { Interferon Alpha } \\
\text { Response }\end{array}$ & 1.51 & Glycolysis & 1.66 & Apical Junction & 1.94 & Apical Junction & 2.04 \\
\hline Estrogen Response Late & 1.50 & Il6 Jak Stat3 Signaling & 1.66 & Kras Signaling Up & 1.83 & Coagulation & 2.01 \\
\hline \multicolumn{2}{|l|}{ Negative Loadings: } & \multicolumn{2}{|l|}{ Negative Loadings: } & \multicolumn{2}{|l|}{ Negative Loadings: } & \multicolumn{2}{|l|}{ Negative Loadings: } \\
\hline Epith. Mesench. Trans. & -3.07 & Tnfa Signaling Via Nfkb & -1.81 & E2F Targets & -8.13 & Myc Targets V1 & -5.97 \\
\hline Coagulation & -2.12 & Myc Targets V1 & -1.74 & G2M Checkpoint & -6.50 & E2F Targets & -5.78 \\
\hline Kras Signaling Dn & -1.80 & Epith. Mesench. Trans. & -1.70 & Myc Targets V1 & -5.56 & G2M Checkpoint & -4.91 \\
\hline $\begin{array}{l}\text { Oxidative } \\
\text { Phosphorylation }\end{array}$ & -1.63 & Apical Junction & -1.63 & mTORc1 Signaling & -4.51 & Oxidative Phosph. & -4.38 \\
\hline Peroxisome & -1.61 & Kras Signaling Up & -1.62 & Oxidative Phosph. & -3.06 & Myc Targets V2 & -4.03 \\
\hline Inflammatory Response & -1.53 & Androgen Response & -1.48 & Dna Repair & -2.87 & mTORc1 Signaling & -3.59 \\
\hline II2 Stat5 Signaling & -1.29 & Kras Signaling Dn & -1.29 & Myc Targets V2 & -2.84 & Dna Repair & -3.55 \\
\hline Myc Targets V2 & -1.25 & Uv Response Dn & -1.23 & Unfolded Protein Resp. & -2.54 & Fatty Acid Metabolism & -2.91 \\
\hline Pancreas Beta Cells & -1.25 & Notch Signaling & -1.19 & Mitotic Spindle & -2.50 & Unfolded Protein Resp. & -2.44 \\
\hline \multicolumn{2}{|c|}{$\begin{array}{l}\text { PC2 } \\
\text { (Separates Taxa By Morphology) }\end{array}$} & \multicolumn{2}{|c|}{$\begin{array}{l}\text { PC2 } \\
\text { (Separates Taxa By Morphology) }\end{array}$} & \multicolumn{2}{|c|}{$\begin{array}{l}\text { PC2 } \\
\text { (Separates Marine From Inland } \\
\text { Taxa) }\end{array}$} & \multicolumn{2}{|c|}{$\begin{array}{l}\text { PC3 } \\
\text { (Separates Scale-Biter From } \\
\text { Taxa) }\end{array}$} \\
\hline Name & NES & Name & NES & Name & NES & Name & NES \\
\hline \multicolumn{2}{|l|}{ Positive Loadings: } & \multicolumn{2}{|l|}{ Positive Loadings: } & \multicolumn{2}{|l|}{ Positive Loadings: } & \multicolumn{2}{|l|}{ Positive Loadings: } \\
\hline Myc Targets V1 & 3.98 & Myogenesis & 2.92 & E2F Targets & 6.93 & Kras Signaling Dn & 2.86 \\
\hline Oxidative Phosph. & 3.10 & Kras Signaling Up & 2.27 & Myc Targets V1 & 5.41 & Uv Response Dn & 2.64 \\
\hline Dna Repair & 2.83 & Interferon Gamma Resp. & 2.21 & G2M Checkpoint & 4.95 & Myogenesis & 2.60 \\
\hline E2F Targets & 2.50 & Coagulation & 1.90 & Myc Targets V2 & 3.80 & Epith. Mesench. Trans. & 2.55 \\
\hline Myc Targets V2 & 2.48 & Protein Secretion & 1.83 & Dna Repair & 3.07 & Tgf Beta Signaling & 2.11 \\
\hline G2M Checkpoint & 2.03 & Apical Junction & 1.82 & mTORc1 Signaling & 3.04 & Hedgehog Signaling & 2.06 \\
\hline Mitotic Spindle & 1.87 & Uv Response Dn & 1.79 & $\begin{array}{l}\text { Unfolded Protein } \\
\text { Response }\end{array}$ & 2.86 & Apical Junction & 2.00 \\
\hline Bile Acid Metabolism & 1.66 & Epith. Mesench. Trans. & 1.79 & Oxidative Phosphorylation & 1.96 & Bile Acid Metabolism & 1.96 \\
\hline mTORc1 Signaling & 1.27 & Kras Signaling Dn & 1.74 & Pancreas Beta Cells & 1.74 & $\begin{array}{l}\text { Wnt B-Catenin } \\
\text { Signaling }\end{array}$ & 1.91 \\
\hline \multicolumn{2}{|l|}{ Negative Loadings: } & \multicolumn{2}{|l|}{ Negative Loadings: } & Negative Loadings: & & Negative Loadings: & \\
\hline Hypoxia & -2.76 & G2M Checkpoint & -3.33 & Myogenesis & -3.90 & E2F Targets & -5.20 \\
\hline Epith. Mesench. Trans. & -2.69 & Myc Targets V1 & -2.96 & Tnfa Signaling Via Nfkb & -3.54 & mTORc1 Signaling & -5.05 \\
\hline Estrogen Response Early & -2.28 & E2F Targets & -2.75 & Hypoxia & -3.07 & Myc Targets V1 & -4.85 \\
\hline Pi3K/Akt/mTOR Sig. & -1.87 & Oxidative Phosphorylation & -1.99 & Interferon Gamma Resp. & -2.86 & G2M Checkpoint & -4.03 \\
\hline
\end{tabular}


Table 1 Enrichment (GSEA) of top Hallmark Gene Sets along principal component axes for each stage (Continued)

\begin{tabular}{|c|c|c|c|c|c|c|c|}
\hline Protein Secretion & -1.76 & Myc Targets V2 & -1.95 & Il6 Jak Stat3 Signaling & -2.82 & Myc Targets V2 & -3.76 \\
\hline Tnfa Signaling Via Nfkb & -1.73 & Dna Repair & -1.85 & Epith. Mesench. Trans. & -2.74 & Dna Repair & -3.50 \\
\hline P53 Pathway & -1.63 & Wnt B-Catenin Signaling & -1.72 & Uv Response Dn & -2.66 & Unfolded Protein Resp. & -2.77 \\
\hline Kras Signaling Up & -1.60 & $\begin{array}{l}\text { Unfolded Protein } \\
\text { Response }\end{array}$ & -1.68 & Kras Signaling Up & -2.62 & Oxidative Phosph. & -2.29 \\
\hline Myogenesis & -1.57 & mTORc1 Signaling & -1.52 & P53 Pathway & -2.57 & $\begin{array}{l}\text { Cholesterol } \\
\text { Homeostasis }\end{array}$ & -2.19 \\
\hline
\end{tabular}

Shown are the top 9 hallmark pathways for each PC axis at each stage. Gene sets in bold are significant at FDR $\leq 0.25$. NES normalized enrichment

enriched categories related to Myc signaling, KRAS signaling, fatty acid metabolism, adipogenesis, myogenesis, the epithelial to mesenchymal transition. Genes related to the extracellular matrix (e.g. matrisome) were significantly enriched in multiple comparisons (Additional file 9: Table S6 and Additional file 10: Table S7).

Other enriched categories of note include Wnt/B-catenin signaling, hedgehog signaling, and terms suggestive of modifications to cytokine signaling such as the inflammatory response, TNF alpha signaling, as well as both Interferon alpha and gamma responses. Genes overexpressed in the scale-biter at stages $48 \mathrm{hpf}, 8 \mathrm{dpf}$, and $15 \mathrm{dpf}$ were enriched for functions related to the estrogen response, while genes underexpressed in the durophage at $8 \mathrm{dpf}$ and $15 \mathrm{dpf}$ were enriched for functions related to the estrogen response.

Also of note is that we observed enrichment for pathways related to neuronal development and functioning at $48 \mathrm{hpf}$ and $96 \mathrm{hpf}$ as well as melanogenesis at $8 \mathrm{dpf}$, thereby highlighting both that brain tissue was included in the embryonic stage samples and that our data likely reflect species differences in addition to skull morphology such as behavior and pigmentation (Additional file 9: Table S6 and Additional file 10: Table S7).

\section{Identification of a set of genes that may contribute to jaw morphological variation in pupfishes}

To identify genes in our dataset that might be contributing to skull morphological variation, we found the intersection set of genes at each stage that were differentially expressed (DE; FDR $\leq 0.1$ and $\log 2$ fold change $\geq 0.2$ ) in all three possible comparisons to either the scale-biter or durophage, the two morphologically extreme species (Fig. 4a; Additional file 11: Figure S4). In our study, genes called $\mathrm{DE}$ by edgeR in any pairwise comparison were typically differentially expressed by between 1.2 fold to 1.5 fold at an FDR cutoff of 0.1 (median ranged from 1.3-1.8 fold difference across all comparisons; Additional file 12: Figure S5, Additional file 13: Figure S6, Additional file 14: Figure S7 and Additional file 15: Figure S8). Selecting genes by a more stringent 1.5 -fold or 2-fold change does not affect our major conclusions, though several genes would not be identified (see discussion). Intersection sets identified in this way include 50-600 genes that are over or underexpressed in either the scale-biter or durophage species at a particular stage (Fig. 4b). Below, we refer to these as intersection sets.

Differentially expressed genes in the intersection sets were typically either over or underexpressed in just one taxon relative to the other three (Fig. 4c; Additional file 16: Figure S9). Only between 5 and 18 genes were found to be $\mathrm{DE}$ in both the scale-biter and durophage sets at a given stage. For example, bbs12 was overexpressed in the scale-biter and underexpressed in the durophage at $48 \mathrm{hpf}$. This contrasts to a hypothesized scenario where most differentially expressed genes are alternately up or down regulated in the scale-biter and durophage, with the two omnivore populations being intermediate. Further investigation of differentially expressed genes in the scale-biter and durophage confirm that different sets of $\mathrm{DE}$ genes characterize these extreme phenotypes relative to the omnivores.

Genes in the intersection sets have varied functional roles: growth factor signaling molecules, cell cycle regulators, apoptosis related molecules, extracellular matrix molecules, solute carriers, cytokine/chemokine molecules, and transcription factors known to be involved in bone development and remodeling (Tables 4, 5, 6 and 7; Additional file 17: Table S8, Additional file 18: Table S9, Additional file 19: Table S10, Additional file 20: Table S11, Additional file 21: Table S12, Additional file 22: Table S13, Additional file 23: Table S14 and Additional file 24: Table S15). We find a number of molecules which function in metabolism, fatty acid synthesis and lipid transport, and protein sorting. We find members of five growth factor/paracrine signaling pathways that play roles in bone growth and remodeling including multiple Wnt ligands and the Wnt receptor $f z d 9$, Igf binding proteins igfbp 2 and igfbp5-like, Bmp receptor bmpr $1 b$ among other Tgf- $\beta$ related molecules, hedgehog antagonist hhip1, and a number of cytokine/chemokine ligands and receptors (Tables 4, 5, 6 and 7; Additional file 17: Table S8, Additional file 18: Table S9, Additional file 19: Table S10, Additional file 20: Table S11, Additional file 21: Table S12, Additional file 22: Table S13, 
Table 2 Enrichment (GSEA) of top Hallmark Gene Sets for genes over- or underexpressed in the Scale-biter relative to all other taxa. Genes were pre-ranked by log2 fold change prior to analysis

\begin{tabular}{|c|c|c|c|c|c|c|c|}
\hline \multicolumn{8}{|l|}{48 Hours Post Fertilization } \\
\hline \multicolumn{4}{|l|}{ Overexpressed in Scale-biter: } & \multicolumn{4}{|l|}{ Underexpressed in Scale-biter: } \\
\hline Name & NES & Pvalue & FDR & Name & NES & Pvalue & FDR \\
\hline Epith. Mesench. Trans. & 2.80 & 0.00 & 0.00 & E2F Targets & -3.60 & 0.00 & 0.00 \\
\hline Hypoxia & 2.27 & $2.0 \mathrm{E}-03$ & 0.01 & Myc Targets V1 & -3.23 & 0.00 & 0.00 \\
\hline Kras Signaling Dn & 2.08 & $2.1 \mathrm{E}-03$ & 0.02 & Dna Repair & -3.06 & 0.00 & 0.00 \\
\hline Estrogen Resp. Early & 1.87 & 0.01 & 0.07 & G2M Checkpoint & -2.94 & 0.00 & 2.4E-04 \\
\hline Coagulation & 1.86 & 0.01 & 0.06 & Oxidative Phosph. & -2.60 & 0.00 & $8.8 \mathrm{E}-04$ \\
\hline Tnfa Sig. via Nfkb & 1.81 & 0.02 & 0.07 & Myc Targets V2 & -2.53 & 0.00 & $1.1 \mathrm{E}-03$ \\
\hline Angiogenesis & 1.64 & 0.04 & 0.14 & Mitotic Spindle & -2.29 & $1.9 \mathrm{E}-03$ & $3.6 \mathrm{E}-03$ \\
\hline Myogenesis & 1.64 & 0.03 & 0.12 & Interferon Alpha Resp. & -1.83 & 0.01 & 0.04 \\
\hline P53 Pathway & 1.58 & 0.06 & 0.14 & Mtorc1 Signaling & -1.70 & 0.03 & 0.07 \\
\hline Kras Signaling Up & 1.54 & 0.05 & 0.15 & Fatty Acid Metabolism & -1.65 & 0.03 & 0.08 \\
\hline \multicolumn{8}{|l|}{96 Hours Post Fertilization } \\
\hline \multicolumn{4}{|l|}{ Overexpressed in Scale-biter: } & \multicolumn{4}{|l|}{ Underexpressed in Scale-biter: } \\
\hline Name & NES & Pvalue & FDR & Name & NES & Pvalue & FDR \\
\hline Myc Targets V1 & 2.69 & 0.00 & $1.2 \mathrm{E}-03$ & Bile Acid Metabolism & -2.59 & 0.00 & $2.0 \mathrm{E}-03$ \\
\hline G2M Checkpoint & 1.99 & $2.0 \mathrm{E}-03$ & 0.07 & Myogenesis & -2.44 & 0.00 & $3.8 \mathrm{E}-03$ \\
\hline Androgen Response & 1.69 & 0.03 & 0.21 & Interferon Gamma Resp. & -2.01 & 0.01 & 0.05 \\
\hline E2F Targets & 1.69 & 0.03 & 0.16 & Interferon Alpha Resp. & -1.75 & 0.02 & 0.15 \\
\hline Myc Targets V2 & 1.68 & 0.03 & 0.13 & Inflammatory Response & -1.68 & 0.03 & 0.18 \\
\hline Unfolded Protein Resp. & 1.47 & 0.07 & 0.29 & Adipogenesis & -1.66 & 0.03 & 0.16 \\
\hline Notch Signaling & 1.44 & 0.10 & 0.28 & Protein Secretion & -1.54 & 0.06 & 0.24 \\
\hline Heme Metabolism & 1.40 & 0.11 & 0.29 & Xenobiotic Metabolism & -1.51 & 0.07 & 0.24 \\
\hline Mtorc1 Signaling & 1.25 & 0.18 & 0.47 & Oxidative Phosphorylation & -1.43 & 0.10 & 0.30 \\
\hline Tnfa Signaling Via Nfkb & 1.11 & 0.32 & 0.69 & Kras Signaling Up & -1.41 & 0.10 & 0.28 \\
\hline \multicolumn{8}{|l|}{8 Days Post Fertilization } \\
\hline \multicolumn{4}{|l|}{ Overexpressed in Scale-biter: } & \multicolumn{4}{|l|}{ Underexpressed in Scale-biter: } \\
\hline Name & NES & Pvalue & FDR & Name & Nes & Pvalue & FDR \\
\hline Uv Response Dn & 2.25 & 0.00 & 0.02 & E2F Targets & -5.90 & 0.00 & 0.00 \\
\hline II2 Stat5 Signaling & 2.14 & 0.01 & 0.02 & G2M Checkpoint & -4.88 & 0.00 & 0.00 \\
\hline Kras Signaling Dn & 2.12 & 0.00 & 0.01 & Myc Targets V1 & -4.18 & 0.00 & 0.00 \\
\hline Tnfa Signaling Via Nfkb & 1.80 & 0.02 & 0.07 & Oxidative Phosph. & -3.54 & 0.00 & 0.00 \\
\hline Angiogenesis & 1.59 & 0.05 & 0.17 & Mtorc1 Signaling & -3.42 & 0.00 & 0.00 \\
\hline Estrogen Response Early & 1.58 & 0.04 & 0.15 & Mitotic Spindle & -2.59 & 0.00 & $1.7 \mathrm{E}-04$ \\
\hline Notch Signaling & 1.54 & 0.06 & 0.16 & Fatty Acid Metabolism & -2.37 & 0.00 & $2.3 \mathrm{E}-03$ \\
\hline P53 Pathway & 1.45 & 0.09 & 0.21 & Dna Repair & -2.22 & 0.00 & 0.01 \\
\hline Apical Junction & 1.45 & 0.09 & 0.18 & Interferon Alpha Resp. & -1.82 & 0.02 & 0.05 \\
\hline Inflammatory Response & 1.42 & 0.10 & 0.19 & Glycolysis & -1.79 & 0.02 & 0.06 \\
\hline \multicolumn{8}{|l|}{15 Days Post Fertilization } \\
\hline \multicolumn{4}{|l|}{ Overexpressed in Scale-biter: } & \multicolumn{4}{|l|}{ Underexpressed in Scale-biter: } \\
\hline Name & NES & Pvalue & FDR & Name & NES & Pvalue & FDR \\
\hline Inflammatory Response & 2.25 & $2.0 \mathrm{E}-03$ & 0.02 & Oxidative Phosph. & -5.63 & 0.00 & 0.00 \\
\hline Cholesterol Homeostasis & 2.13 & 2.1E-03 & 0.02 & Myc Targets V1 & -3.70 & 0.00 & 0.00 \\
\hline
\end{tabular}


Table 2 Enrichment (GSEA) of top Hallmark Gene Sets for genes over- or underexpressed in the Scale-biter relative to all other taxa. Genes were pre-ranked by log2 fold change prior to analysis (Continued)

\begin{tabular}{llllllll}
\hline Wnt B-Catenin Signaling & 2.02 & $3.9 \mathrm{E}-03$ & 0.03 & Fatty Acid Metabolism & -2.52 & 0.00 & 0.00 \\
Hedgehog Signaling & 1.94 & 0.01 & 0.04 & Adipogenesis & -2.50 & 0.00 & $2.3 \mathrm{E}-04$ \\
Pi3K Akt Mtor Signaling & 1.94 & 0.01 & 0.03 & Dna Repair & -2.46 & 0.00 & $1.9 \mathrm{E}-04$ \\
Allograft Rejection & 1.83 & 0.02 & 0.05 & E2F Targets & -2.32 & 0.00 & $2.6 \mathrm{E}-03$ \\
Uv Response Dn & 1.72 & 0.02 & 0.08 & Bile Acid Metabolism & -2.19 & $1.9 \mathrm{E}-03$ & 0.01 \\
Complement & 1.70 & 0.03 & 0.07 & Tnfa Signaling Via Nfkb & -1.71 & 0.02 & 0.09 \\
Estrogen Response Early & 1.50 & 0.08 & 0.16 & Xenobiotic Metabolism & -1.55 & 0.06 & 0.17 \\
Apical Junction & 1.41 & 0.10 & 0.23 & Spermatogenesis & -1.51 & 0.07 & 0.19 \\
\hline
\end{tabular}

Shown are the top 10 genesets shown for each analysis. Gene sets significant at FDR $\leq 0.25$ shown in bold

NES Normalized Enrichment, Pvalue Nominal $P$ value, FDR False Discover Rate (Q value)

Additional file 23: Table S14 and Additional file 24: Table S15).

Overrepresentation analysis indicated that intersection sets were generally not significantly enriched for GO terms at an FDR threshold of $\leq 0.1$ (Additional file 25: Table S16, Additional file 26: Table S17, Additional file 27: Table S18, Additional file 28: Table S19, Additional file 29: Table S20 and Additional file 30: Table S21). Notable exceptions were that the intersection set for the scale-biter at $48 \mathrm{hpf}$ was significantly enriched for genes related to cilium and plasma membrane, and the intersection set for the scale-biter at $8 \mathrm{dpf}$ was enriched for carboxylic acid and oxoacid metabolic processes.

To further investigate whether genes known to affect bony skull elements are within the intersection sets, we curated a list of over 1700 genes from databases and from literature searches. We downloaded lists of genes that have known craniofacial phenotypes from the Zebrafish Model Organism Database (ZFIN), the Mouse Genome Informatics Database (MGI), and NCBI PhenotypeGenotype Integrator (PheGenI) using the search terms "Cranial Cartilage", "Cranium", "Pharyngeal Arch Cartilage", "Ventral Mandibular Arch", "Craniofacial Development" (ZFIN), "Jaw", "Maxilla", "Skull”, "Craniofacial" (MGI), and "Face", "Jaw Abnormalities", "Cleft Lip", "Cleft Palate" (PheGenI). We also downloaded genes annotated by the Gene Ontology Consortium with functions related to craniofacial morphology or bone.

More than $95 \%$ of the genes discovered through intersection sets have not been previously annotated with functions directly related to craniofacial morphology or bone (Fig. 4b,c). Of the genes in the intersection sets that are annotated to affect bone, most are also annotated to have craniofacial phenotypes indicating that our literature and database searches were likely to have been fairly comprehensive (Fig. 4b,c). To assess whether we identified a greater number of annotated genes in the intersection sets than would be expected by chance, we calculated a probability distribution by identifying the number of curated genes in 1000 randomly drawn sets of equal size to each of the intersection sets. We found that none of the sets contained significantly more genes with previously researched craniofacial phenotypes than would be expected by chance alone suggesting that the intersection sets are not statistically enriched for genes already known, largely from biomedical research, to affect skull morphology.

The lack of statistically detected enrichment does not necessarily eliminate curated genes as being important. For example, if morphological differences are produced by modified expression of only a few genes then this would not be detected by overrepresentation analyses. Thus, we also consider potentially relevant annotated genes found to be DE in our dataset (Fig. 4c). We find multiple Wnt ligands either overexpressed in the scalebiter (wnt11), or underexpressed in in the durophage $(w n t 1, w n t 10 b)$ at $48 \mathrm{hpf}$. Wnt signaling is well known to affect craniofacial morphology [25-27, 29, 51]. While we note that Wnt ligands were typically DE by less than 1.5 fold, these data along with GSEA results (Tables 1, 2 and 3; Additional file 5: Table S2, Additional file 6: Table S3, Additional file 7: Table S4, Additional file 8: Table S5, Additional file 9: Table S6 and Additional file 10: Table S7), suggest that Wnt signaling may be differentially activated in the two species with extreme jaw morphologies at an early stage of development.

A number of transcription factors are within the intersection sets, including six1, twsg1, sall4 at $48 \mathrm{hpf}$, fosab, ncoa3 at $96 \mathrm{hpf}$, and gata1, sall4, ncoa3, and maf at 8 dpf (Fig. 4c). We found cytokine/chemokine signaling molecules with known craniofacial phenotypes including a putative macrophage colony stimulating factor 1 $(c s f 1 b)$ at $96 \mathrm{hpf}$, and its receptor $c s f 1 r$ at $8 \mathrm{dpf}$. Both $c s f 1 b$ and $c s f 1 r$, are known to play important roles in osteoclast differentiation [52-54]. Other genes of note include slc24a4 (associated with enamel formation in human) [55], smoc1 (associated with craniofacial morphology in human) [56, 57], lbh (craniofacial evolution in cichlids) [58], ednrb (endothelin signaling) [59, 60], bambi (Bmp signaling and differential expression during bone remodeling) [61], and $d k k 3 b$ (craniofacial evolution in finches) [62]. 
Table 3 Enrichment (GSEA) of top Hallmark Gene Sets for genes over- or underexpressed in the Durophage relative to all other taxa. Genes were pre-ranked by log2 fold change prior to analysis

\begin{tabular}{|c|c|c|c|c|c|c|c|}
\hline \multicolumn{8}{|l|}{48 Hours Post Fertilization } \\
\hline Overexpressed in Durophage: & & & & Underexpressed in Durophage: & & & \\
\hline Name & NES & Pvalue & FDR & Name & NES & Pvalue & FDR \\
\hline Inflammatory Response & 1.74 & 0.02 & 0.39 & E2F Targets & -2.77 & 0.00 & 0 \\
\hline Pancreas Beta Cells & 1.65 & 0.04 & 0.31 & Myc Targets V1 & -2.42 & 0.00 & $2.74 \mathrm{E}-03$ \\
\hline Uv Response Dn & 1.62 & 0.04 & 0.23 & G2M Checkpoint & -2.35 & $2.0 \mathrm{E}-03$ & 0.01 \\
\hline Mitotic Spindle & 1.53 & 0.05 & 0.27 & Oxidative Phosphory. & -2.30 & 0 & 4.76E-03 \\
\hline Epith.Mesench.Trans. & 1.43 & 0.10 & 0.34 & Hypoxia & -2.15 & $2.0 \mathrm{E}-03$ & 0.01 \\
\hline Myogenesis & 1.43 & 0.08 & 0.29 & Adipogenesis & -1.85 & 0.01 & 0.06 \\
\hline Hedgehog Signaling & 1.31 & 0.16 & 0.38 & Protein Secretion & -1.73 & 0.02 & 0.11 \\
\hline Kras Signaling Up & 1.17 & 0.26 & 0.57 & Pi3K/Akt/mTOR Sig. & -1.72 & 0.02 & 0.10 \\
\hline II2 Stat5 Signaling & 1.12 & 0.30 & 0.59 & Fatty Acid Metabolism & -1.67 & 0.04 & 0.11 \\
\hline Apical Junction & 0.94 & 0.53 & 0.93 & Myc Targets V2 & -1.64 & 0.04 & 0.12 \\
\hline \multicolumn{8}{|l|}{96 Hours Post Fertilization } \\
\hline Overexpressed in Durophage: & & & & Underexpressed in Durophage: & & & \\
\hline Name & NES & Pvalue & FDR & Name & NES & Pvalue & FDR \\
\hline E2F Targets & 2.01 & 0.01 & 0.12 & Hypoxia & -2.42 & 0.00 & 0.01 \\
\hline Mitotic Spindle & 1.95 & 0.01 & 0.08 & Tnfa Signaling Via Nfkb & -1.94 & 0.01 & 0.09 \\
\hline Myogenesis & 1.83 & 0.01 & 0.11 & Protein Secretion & -1.77 & 0.01 & 0.15 \\
\hline Bile Acid Metabolism & 1.73 & 0.03 & 0.15 & Oxidative Phosphorylation & -1.55 & 0.06 & 0.31 \\
\hline Inflammatory Response & 1.71 & 0.02 & 0.13 & Epith. Mesench.Trans. & -1.45 & 0.09 & 0.40 \\
\hline Interferon Alpha Resp. & 1.70 & 0.02 & 0.12 & Cholesterol Homeostasis & -1.34 & 0.14 & 0.53 \\
\hline Myc Targets V1 & 1.54 & 0.06 & 0.22 & II6 Jak Stat3 Signaling & -1.33 & 0.13 & 0.46 \\
\hline Dna Repair & 1.53 & 0.06 & 0.20 & Estrogen Response Late & -1.32 & 0.15 & 0.42 \\
\hline Uv Response Dn & 1.51 & 0.06 & 0.20 & Kras Signaling Up & -1.31 & 0.14 & 0.39 \\
\hline Pi3KAkt/mTOR Sig. & 1.39 & 0.12 & 0.30 & Estrogen Early Resp. & -1.30 & 0.16 & 0.36 \\
\hline \multicolumn{8}{|l|}{8 Days Post Fertilization } \\
\hline Overexpressed in Durophage: & & & & Underexpressed in Durophage: & & & \\
\hline Name & NES & Pvalue & FDR & Name & Nes & Pvalue & FDR \\
\hline Myc Targets V1 & 3.23 & 0.00 & 0.00 & Protein Secretion & -2.34 & $2.1 E-03$ & 0.01 \\
\hline E2F Targets & 3.16 & 0.00 & 0.00 & Coagulation & -2.16 & $1.9 \mathrm{E}-03$ & 0.02 \\
\hline Allograft Rejection & 2.89 & 0.00 & 0.00 & Uv Response Dn & -1.83 & 0.02 & 0.11 \\
\hline Oxidative Phosph. & 2.85 & 0.00 & 0.00 & Estrogen Response Early & -1.80 & 0.03 & 0.10 \\
\hline Dna Repair & 2.31 & 0.00 & $4.3 \mathrm{E}-03$ & Estrogen Response Late & -1.78 & 0.02 & 0.09 \\
\hline Myc Targets V2 & 1.90 & 4.1E-03 & 0.04 & Hypoxia & -1.65 & 0.04 & 0.15 \\
\hline G2M Checkpoint & 1.82 & 0.02 & 0.05 & Kras Signaling Dn & -1.58 & 0.05 & 0.17 \\
\hline Mitotic Spindle & 1.67 & 0.04 & 0.10 & Notch Signaling & -1.57 & 0.05 & 0.16 \\
\hline ROS Pathway & 1.61 & 0.04 & 0.12 & Cholesterol Homeostasis & -1.40 & 0.09 & 0.30 \\
\hline Interferon Gamma Resp. & 1.40 & 0.11 & 0.26 & Hedgehog Signaling & -1.38 & 0.11 & 0.28 \\
\hline \multicolumn{8}{|l|}{15 Days Post Fertilization } \\
\hline Overexpressed in Durophage: & & & & Underexpressed in Durophage: & & & \\
\hline Name & NES & Pvalue & FDR & Name & NES & Pvalue & FDR \\
\hline Myogenesis & 3.59 & 0.00 & 0.00 & G2M Checkpoint & -4.25 & 0.00 & 0.00 \\
\hline Allograft Rejection & 3.54 & 0.00 & 0.00 & E2F Targets & -4.05 & 0.00 & 0.00 \\
\hline
\end{tabular}


Table 3 Enrichment (GSEA) of top Hallmark Gene Sets for genes over- or underexpressed in the Durophage relative to all other taxa. Genes were pre-ranked by log2 fold change prior to analysis (Continued)

\begin{tabular}{llllllll}
\hline Interferon Gamma Resp. & 2.31 & $4.0 \mathrm{E}-03$ & 0.01 & Mtorc1 Signaling & -2.97 & 0.00 & 0.00 \\
Inflammatory Response & 2.16 & 0 & 0.01 & Cholesterol Homeostasis & -2.69 & 0.00 & $2.2 \mathrm{E}-04$ \\
Bile Acid Metabolism & 2.06 & $2.0 \mathrm{E}-03$ & 0.01 & Myc Targets V1 & -2.31 & 0.00 & $3.5 \mathrm{E}-03$ \\
II2 Stat5 Signaling & 1.94 & 0.01 & 0.03 & Oxidative Phosphory. & -2.31 & 0.00 & $2.9 \mathrm{E}-03$ \\
Interferon Alpha Resp. & 1.85 & 0.01 & 0.04 & Mitotic Spindle & -2.17 & $1.9 \mathrm{E}-03$ & 0.01 \\
P53 Pathway & 1.82 & 0.01 & 0.04 & Estrogen Response Late & -1.65 & 0.04 & 0.11 \\
Uv Response Dn & 1.74 & 0.02 & 0.06 & Adipogenesis & -1.51 & 0.06 & 0.18 \\
Kras Signaling Up & 1.73 & 0.02 & 0.06 & Fatty Acid Metabolism & -1.50 & 0.06 & 0.17 \\
\hline
\end{tabular}

Shown are the top 10 gene sets shown for each analysis. Gene sets significant at FDR $\leq 0.25$ shown in bold

NES Normalized Enrichment, Pvalue Nominal $P$ value, FDR False Discover Rate (Q value)

\section{Constitutive differential expression of genes in the scale-biter and durophage taxa}

Gene expression is dynamic, and it is possible that genes will be differentially expressed at only critical periods of time during development. Alternatively, many genes are constitutively expressed and may be differentially expressed over relatively long blocks of developmental time. At a transcriptomic level different genes could follow either of these patterns. We asked what percentage of genes in the intersection sets follow a pattern of being differentially expressed at a single time point versus what percentage are differentially expressed over more than one time point.

Of the genes in all four scale-biter intersection sets, $227(22.0 \%)$ occur in an intersection set at two or more stages. Similarly, 79 (18.5\%) of all durophage genes occur in an intersection set at two or more stages. In fact, most of these genes may be differentially expressed over the entire course of developmental stages sampled if we relax the criterion of statistical significance (Fig. 5). Genes that were overexpressed or underexpressed at one stage tended to be overexpressed or underexpressed respectively at all other stages as well, even if not sufficiently so to be deemed statistically significant at an FDR $\leq 0.1$. However, we recognize that there can be important functional impact of even slight differential expression [63]. Therefore, when differential expression is in the same direction (over- or underexpressed) in all four developmental stages sampled, we refer to these genes as constitutively differentially expressed.

This pattern holds even when the level at which a gene is expressed changes through development as seen in the representative gene boxplots (e.g. igfbp5-like in Fig. 5). Other genes, however, did not follow this pattern throughout the experiment. For instance, an interleukin $12 \mathrm{~b}$ receptor paralog is expressed in the scale-biter at levels typical for larval pupfish of all 4 taxa, but this gene is not differentially expressed at post-hatching stages (Fig. 5). These results suggest that while $\sim 80 \%$ of genes in our intersection sets are differentially expressed at only a single time point during development, approximately $20 \%$ of the genes in our scale-biter and durophage intersection sets are constitutively differentially expressed during the period of development we sampled. This may be an underestimate of constitutive expression and we suspect that a much greater proportion of genes are constitutively differentially expressed (see discussion).

\section{Expression of previously identified candidate genes in pupfishes}

A fundamental question in evolutionary biology concerns the extent to which the genetic sources of phenotypic diversity are shared across taxa. Early work identified modifications to Bmp4 and calmodulin associated with jaw diversification in both African cichlids and Galapagos finches [20, 21, 64], as well as modification to Bmp4 contributing to beak differences in ducks and chickens [65]. Given the great divergence time between cichlids and finches, these studies raised the possibility that modifications to the expression of Bmp4 and calmodulin might be responsible for jaw diversity in other taxa, or at least across all vertebrates.

We asked whether candidate genes known to produce jaw diversity in other vertebrates were also differentially expressed at any stage among distinct jaw phenotypes of pupfishes. We also explored whether genes affecting cranial cartilages identified from a zebrafish mutagenesis screen were differentially expressed among species of pupfishes with different jaw phenotypes [66, 67]. In contrast to the intersection sets, here we are interested in genes that may be differentially expressed in even a single pairwise comparison.

Expression levels of $b m p 4, b m p 2$, calmodulin, ptch1, $\beta$-catenin and tgfr 2 , genes associated with changes to jaw shape (bmp4, calmodulin, tgfr 2, ptch1) or size (bmp2) in finches or cichlids, are expressed at similar levels among pupfishes at all four stages (Fig. 6a; data for some genes not plotted). In contrast, however, there are several genes differentially expressed among pupfishes as well as cichlids and finches. Paralogs to camkII 
a

Identify DE genes (FDR $\leq 0.1)$ for all pairwise comparisons at a given developmental stage

Scale-biter Intersection Sets

Scale-biter

Scale-biter

vs.

vs.

Inland omnivore Marine omnivore

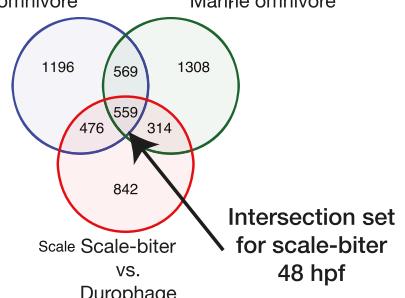

Durophage Durophage

and omnivore vs.

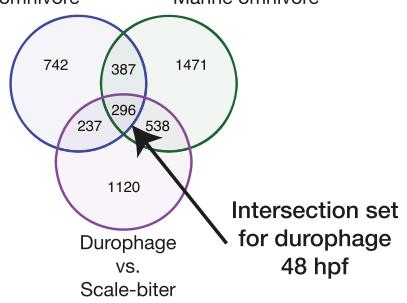

b

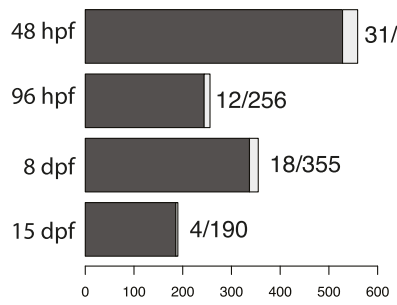

$31 / 559$

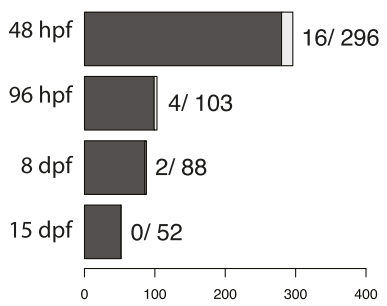

\section{C}

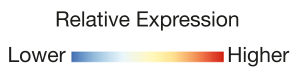

Relative Expression

Lower $=$ Higher

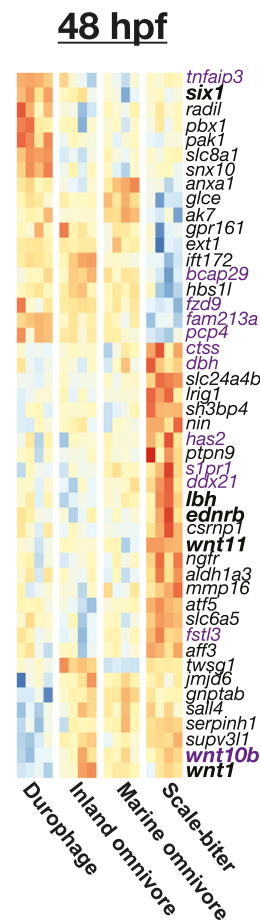

$\underline{96 \mathrm{hpf}}$

$8 \mathrm{dpf}$
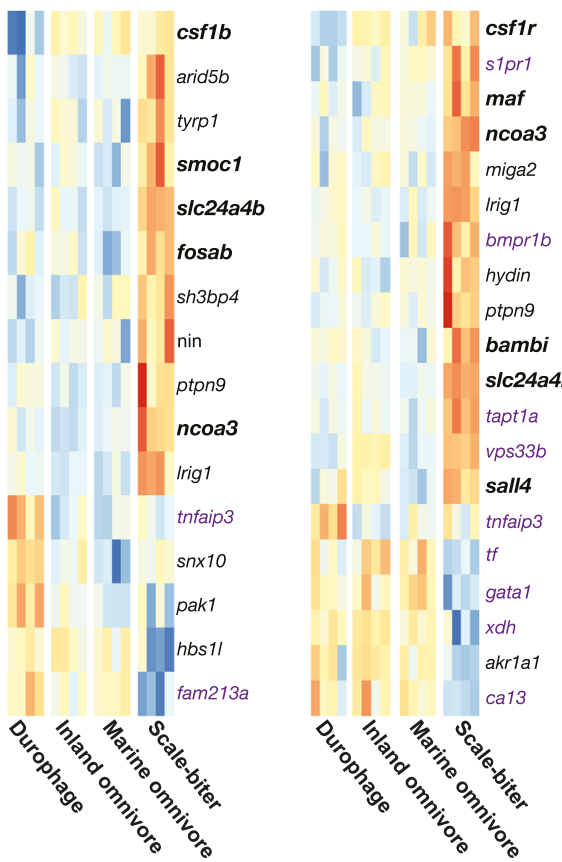

$15 \mathrm{dpf}$

Fig. 4 Differentially expressed (DE) genes for four developmental stages of cranial development in four pupfish taxa. These DE genes include genes which may be contributing to jaw morphological differences among taxa. a Genes associated with the development of distinctive skull morphologies were selected as the intersection of genes differentially expressed in all pairwise comparisons at a given stage to either the scale-biter or durophage, the two species with extreme morphologies. $\mathbf{b}$ Histograms show number of genes in each intersection. White portion of bars correspond to the number of genes in each set that are annotated to affect bone. Numbers to right of bars give number of genes annotated to affect bone and total numbers of genes in each intersection set. $\mathbf{c}$ Relative expression of genes annotated to affect skull bones (black) or simply bone (purple) at each stage in our dataset highlight the relative over- and underexpression of wht ligands in the scale-biter and durophage respectively at $48 \mathrm{hpf}$, and that a number of genes are differentially expressed at multiple stages. Genes in bold are highlighted in the text 
Table 4 Select genes from all four intersection sets that are overexpressed in the scale-biter

\begin{tabular}{|c|c|c|c|c|c|}
\hline \multirow{2}{*}{$\frac{\text { Gene Group }}{\text { Apoptosis }}$} & \multirow[t]{2}{*}{ Gene Name } & \multicolumn{3}{|c|}{ Intersection Set } & \\
\hline & & & & & \\
\hline aifm3 & apoptosis inducing factor, mitochondria associated 3 & 48hpf & & 8dpf & \\
\hline aven & apoptosis, caspase activation inhibitor & 48hpf & 96hpf & & \\
\hline bnip3 & BCL2/adenovirus E1B $19 \mathrm{kDa}$ interacting protein 3 & 48hpf & & & \\
\hline LOC107103375 & caspase recruitment domain-containing protein 8-like & & 96hpf & & \\
\hline \multicolumn{6}{|l|}{ Bardet-Biedl syndrome } \\
\hline$b b s 12$ & Bardet-Biedl syndrome 12 & 48hpf & & & \\
\hline \multicolumn{6}{|l|}{ Calcium Signaling } \\
\hline anxa11 & annexin A11 & 48hpf & 96hpf & & \\
\hline calb2 & calbindin 2 & 48hpf & & & \\
\hline calcrl & calcitonin receptor like receptor & 48hpf & & & \\
\hline LOC107082646 & calpain-1 catalytic subunit-like & 48hpf & & & \\
\hline LOC107081484 & calpain-1 catalytic subunit-like & 48hpf & & & \\
\hline LOC107102261 (capn1a) & calpain-1 catalytic subunit-like & 48hpf & & & \\
\hline LOC107092503 & calpain-9-like & 48hpf & 96hpf & $8 d p f$ & \\
\hline LOC107099392 & calpain-9-like & & 96hpf & & \\
\hline clstn3 & calsyntenin 3 & 48hpf & & & \\
\hline LOC107084037 (s100 s) & protein S100-A1-like & 48hpf & 96hpf & & \\
\hline \multicolumn{6}{|l|}{ Cell Adhesion } \\
\hline ncam1 & neural cell adhesion molecule 1 & 48hpf & & & \\
\hline LOC107088148 & cadherin-like protein 26 & & & 8dpf & \\
\hline LOC107084761 & claudin-9-like & & & 8dpf & \\
\hline \multicolumn{6}{|l|}{ Cell Cycle } \\
\hline bora & bora, aurora kinase $\mathrm{A}$ activator & 48hpf & 96hpf & & \\
\hline \multicolumn{6}{|l|}{ Cytokine/Chemokine } \\
\hline LOC107100215 (cxcr3.2) & $\mathrm{C}-\mathrm{X}-\mathrm{C}$ chemokine receptor type 3 -like & 48hpf & & & \\
\hline LOC107100210 & C-X-C chemokine receptor type 4-B-like & 48hpf & & & \\
\hline LOC107091150 (il12rb2l) & interleukin-12 receptor subunit beta-2-like & 48hpf & 96hpf & & \\
\hline$i / 4 r$ & interleukin 4 receptor & & & & $15 \mathrm{dpf}$ \\
\hline LOC107087156 (i/2rb) & interleukin-2 receptor subunit beta-like & & & & $15 \mathrm{dpf}$ \\
\hline LOC107092801 (ngfr) & tumor necrosis factor receptor superfamily member 16-like & 48hpf & & & \\
\hline $\operatorname{tnfrsf21}$ & tumor necrosis factor receptor superfamily member 21 & 48hpf & 96hpf & & \\
\hline clcfi & cardiotrophin-like cytokine factor 1 & & & $8 \mathrm{dpf}$ & \\
\hline \multicolumn{6}{|l|}{ Chaperone/Heat Shock } \\
\hline LOC107090055 (dnaja3b) & dnaJ homolog subfamily A member 3, mitochondrial-like & & 96hpf & & \\
\hline
\end{tabular}

Lipid Transport

\section{LOC107095514 \\ apof}

Growth Factor

LOC107086851 (ednrba)

LOC107083579 (epha6)

LOC107084161

flt 1 heat shock $70 \mathrm{kDa}$ protein $12 \mathrm{~A}$-like apolipoprotein A-IV-like $\quad 48 \mathrm{hpf}$

apolipoprotein F 48hpf

endothelin B receptor-like $\quad$ 48hpf

ephrin type-A receptor 6-like 48hpf

fibroblast growth factor 13-like 48hpf

fms-related tyrosine kinase $1 \quad$ 48hpf 
Table 4 Select genes from all four intersection sets that are overexpressed in the scale-biter (Continued)

\begin{tabular}{|c|c|c|c|c|c|}
\hline \multicolumn{6}{|l|}{ BMP } \\
\hline bambi & \multicolumn{3}{|l|}{ BMP and activin membrane-bound inhibitor } & \multicolumn{2}{|l|}{$8 \mathrm{dpf}$} \\
\hline bmprib & \multicolumn{3}{|l|}{ bone morphogenetic protein receptor type IB } & \multicolumn{2}{|l|}{$8 \mathrm{dpf}$} \\
\hline \multicolumn{6}{|l|}{ IFG signaling } \\
\hline igfbp2 & insulin like growth factor binding protein 2 & 48hpf & 96hpf & $8 \mathrm{dpf}$ & $15 \mathrm{dpf}$ \\
\hline LOC107084241 & insulin-like growth factor-binding protein 5 & 48hpf & 96hpf & $8 \mathrm{dpf}$ & $15 \mathrm{dpf}$ \\
\hline igflr1 & IGF like family receptor 1 & & & $8 \mathrm{dpf}$ & \\
\hline \multicolumn{6}{|l|}{ Matrix } \\
\hline adam 22 & ADAM metallopeptidase domain 22 & 48hpf & & & \\
\hline crtap & cartilage associated protein & 48hpf & 96hpf & & \\
\hline LOC107101759 & collagen alpha-1(XXVIII) chain-like & 48hpf & & & \\
\hline $\mathrm{col} / 5 a_{3}$ & collagen, type $V$, alpha 3 & 48hpf & & & \\
\hline col16al & collagen, type XVI, alpha 1 & 48hpf & & & \\
\hline LOC107098087 (col8a1b) & collagen alpha-1(VIII) chain-like & & 96hpf & & \\
\hline LOC107101792 (col15a1b) & collagen alpha-1(XV) chain-like & & 96hpf & & \\
\hline LOC107084752 & integrin beta-3-like & 48hpf & & & \\
\hline$f_{s t} / 3$ & follistatin-like 3 (secreted glycoprotein) & 48hpf & & & \\
\hline LOC107092333 (fndc) & fibronectin type III domain-containing protein 7-like & 48hpf & & & \\
\hline LOC107081663 (mmp16b) & matrix metalloproteinase-16-like & 48hpf & & & \\
\hline otol1 & otolin 1 & 48hpf & & & \\
\hline LOC107089461 (phlda2) & pleckstrin homology-like domain family A member 2 & 48hpf & & & \\
\hline plekhh2 & pleckstrin homology, MyTH4 and FERM domain containing $\mathrm{H} 2$ & 48hpf & 96hpf & $8 \mathrm{dpf}$ & $15 \mathrm{dpf}$ \\
\hline plod1 & procollagen-lysine, 2-oxoglutarate 5-dioxygenase 1 & 48hpf & & & \\
\hline LOC107097692 (sparcl1) & SPARC-like protein 1 & 48hpf & & & \\
\hline smoct & SPARC related modular calcium binding 1 & & 96hpf & & \\
\hline fst/4 & follistatin-like 4 & & & $8 \mathrm{dpf}$ & \\
\hline LOC107101284 & thrombospondin type-1 domain-containing protein 7A-like & & & $8 \mathrm{dpf}$ & \\
\hline LOC107101285 & thrombospondin type-1 domain-containing protein 7A-like & & & $8 \mathrm{dpf}$ & \\
\hline \multicolumn{6}{|l|}{ Muscle } \\
\hline LOC107095331 & myosin-16-like & 48hpf & & & \\
\hline LOC107082773 (tpm1) & tropomyosin alpha-1 chain-like & 48hpf & & & \\
\hline LOC107089161 & troponin I, slow skeletal muscle-like & 48hpf & 96hpf & & \\
\hline \multicolumn{6}{|l|}{ Tgf-beta } \\
\hline tgfbi & transforming growth factor beta induced & 48hpf & & & \\
\hline \multicolumn{6}{|l|}{ Transciption Factor } \\
\hline evx1 & even-skipped homeobox 1 & 48hpf & & & \\
\hline meox1 & mesenchyme homeobox 1 & 48hpf & & & \\
\hline sp4 & Sp4 transcription factor & 48hpf & 96hpf & 8dpf & \\
\hline LOC107087726 & sal-like protein 1 & & 96hpf & & \\
\hline LOC107093901 (nсоа3) & nuclear receptor coactivator 3-like & & 96hpf & $8 \mathrm{dpf}$ & \\
\hline sall4 & spalt-like transcription factor 4 & & & $8 \mathrm{dpf}$ & \\
\hline LOC107084340 (mafb) & transcription factor Maf-like & & & $8 \mathrm{dpf}$ & \\
\hline \multicolumn{6}{|l|}{ Wnt } \\
\hline wnt11 & wingless-type MMTV integration site family member 11 & 48hpf & & & \\
\hline$i l k a p$ & ILK associated serine/threonine phosphatase & & 96hpf & & \\
\hline
\end{tabular}


Table 4 Select genes from all four intersection sets that are overexpressed in the scale-biter (Continued)

\begin{tabular}{|c|c|c|c|c|c|}
\hline \\
\hline \multicolumn{6}{|c|}{ limb bud and heart development } \\
\hline LOC107088691 (npdc1a) & $\begin{array}{l}\text { neural proliferation differentiation and control } \\
\text { protein } 1 \text {-like }\end{array}$ & 48hpf & & & \\
\hline rps $6 \mathrm{k} / 1$ & ribosomal protein S6 kinase like 1 & $48 \mathrm{hpf}$ & 96hpf & & \\
\hline LOC107087452 & ribosomal protein S6 kinase beta-1-like & & & $8 \mathrm{dpf}$ & $15 \mathrm{dpf}$ \\
\hline LOC107095875 & sex comb on midleg-like protein 4 & 48hpf & & & \\
\hline LOC107102698 & tissue factor-like & 48hpf & & & \\
\hline slc24a4 & $\begin{array}{l}\text { solute carrier family } 24 \text { (sodium/potassium/calcium exchanger), } \\
\text { member } 4\end{array}$ & 48hpf & 96hpf & $8 \mathrm{dpf}$ & \\
\hline acp7 & acid phosphatase 7 , tartrate resistant (putative) & & & $8 \mathrm{dpf}$ & \\
\hline vwal & von Willebrand factor A domain containing 1 & & & $8 \mathrm{dpf}$ & \\
\hline vwde & von Willebrand factor D and EGF domains & & & $8 \mathrm{dpf}$ & \\
\hline LOC107081298 & von Willebrand factor-like & & & $8 \mathrm{dpf}$ & \\
\hline clgalt1 & $\begin{array}{l}\text { core } 1 \text { synthase, glycoprotein- } \mathrm{N} \text {-acetylgalactosamine } \\
\text { 3-beta-galactosyltransferase } 1\end{array}$ & & & & $15 \mathrm{dpf}$ \\
\hline mpeg1 & macrophage expressed 1 & & & & $15 \mathrm{dpf}$ \\
\hline
\end{tabular}

Shown are pupfish gene names with zebrafish gene names in parentheses

and other calmodulin dependent kinases are differentially expressed among pupfish taxa (Additional file 31: Table S22), and shh tends to be slightly overexpressed in the scale-biter (Fig. 6a). The Wnt signaling antagonist $d k k 3 b$, but not $d k k 3 a$, is underexpressed in the scalebiter at $15 \mathrm{dpf}$. The transcriptional activator, $l b h$, is overexpressed in the scale-biter at $48 \mathrm{hpf}$ (Fig. 4) [58].

Three candidate genes emerging from a zebrafish mutagenesis screen, wnt11, ednra, and ednrb [59, 66, 67], are overexpressed in the scale-biter, and may contribute to the extreme jaw morphology of this species. Wnt11 function is absent or reduced in zebrafish Silberblick (wnt11/slb) mutants that exhibit dramatic abnormalities to the anterior portions of the skull $[23,51,66]$ reminiscent of the differences in anterior skull bone morphology between the scale-biters and other species of pupfishes (e.g. oral jaw bone length). We also find that ednra and $e d n r b$, receptors for $E d n 1$ signaling, are differentially expressed across species of pupfishes (Fig. 6b). $E d n 1$ was identified as the zebrafish Sucker (edn1/suc) mutant, and work in mouse and chicken has indicated that disrupting the expression of Ednra also results in abnormal jaw morphologies [59, 68-70].

\section{Expression in pupfishes of osteoblast and osteoclast marker genes}

Genes found to be differentially expressed among pupfishes contained a number of molecules known to affect osteoblast and osteoclast differentiation, proliferation, and apoptosis. We were thus interested in whether genes commonly used as genetic markers of osteoblast and osteoclast activity were differentially expressed. We investigated more closely the expression patterns of four osteoblast marker genes $r u n x 2, r a n k l, c s f 1 b$, and alkaline phosphatase, as well as six osteoclast expressing genes including rank, calcitonin receptors calcrl and calcr, cathepsin $\mathrm{K}$, and acp5 (tartrate resistant acid phosphatase) in order to determine whether there was a signal of cell types being more or less active or abundant in some species relative to others.

Genes associated with osteoblast activity were typically not differentially expressed among species of pupfishes (Fig. 7). The one exception was a putative ortholog of the zebrafish macrophage colony stimulating factor $1 \mathrm{~b}$ (csf1b), a gene also identified in the intersection sets, that tended to be constitutively underexpressed in the durophage at all developmental stages. Mammalian osteoblast/stromal cells are known to express Csf 1 as a molecule that affects osteoclast differentiation, recruitment, and activity [52-54].

A number of osteoclast expressing genes were differentially expressed in our dataset. Calcitonin receptors and cathepsin $\mathrm{K}$ were slightly overexpressed in the scalebiter at embryonic stages of development, and both rank and acp 5 were overexpressed in the scale-biter at $15 \mathrm{dpf}$, during a period of larval growth. These data suggest that osteoclast activity or number may differ among species of pupfishes, with perhaps osteoclast activity lower in the durophage and relatively higher in the scale-biter. Intriguingly, osteoclast marker genes were not differentially expressed in all pairwise comparisons and genes that were differentially expressed tended to be DE at different stages. This perhaps suggests that either only osteoclast activity, and not number, is differentially 
Table 5 Select genes from all four intersection sets that are underexpressed in the scale-biter

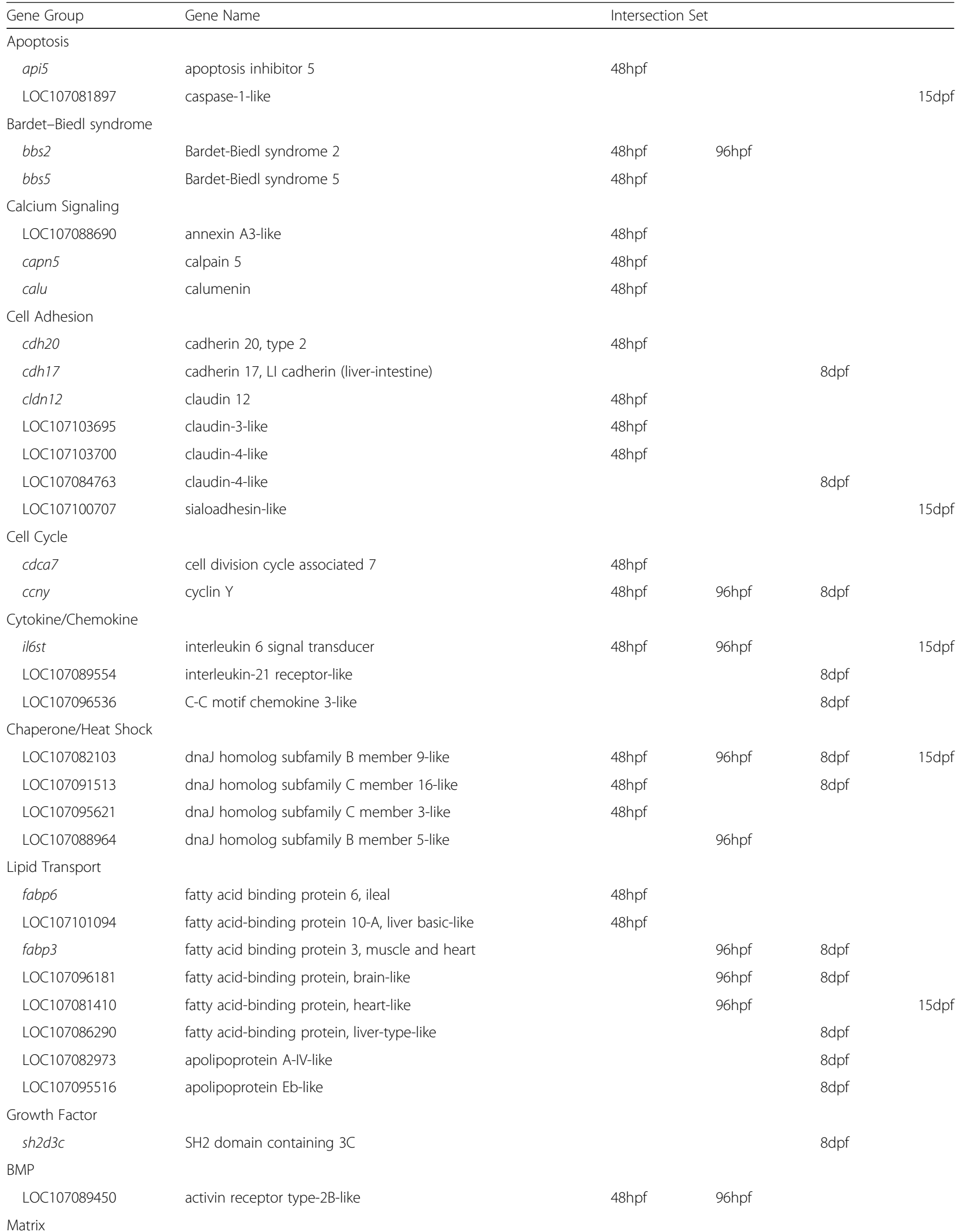


Table 5 Select genes from all four intersection sets that are underexpressed in the scale-biter (Continued)

\begin{tabular}{|c|c|c|c|c|c|}
\hline LOC107082466 & cartilage acidic protein 1-like & 48hpf & 96hpf & & $15 \mathrm{dpf}$ \\
\hline LOC107093562 & collagen alpha-1(XXVIII) chain-like & 48hpf & & & \\
\hline LOC107094934 & collagen alpha-2(I) chain-like & & 96hpf & & \\
\hline LOC107086858 & collagen alpha-4(IV) chain-like & & & $8 \mathrm{dpf}$ & \\
\hline LOC107097307 & $\begin{array}{l}\text { disintegrin and metalloproteinase domain-containing } \\
\text { protein 10-like }\end{array}$ & 48hpf & & & \\
\hline$f_{s} d 1$ & fibronectin type III and SPRY domain containing 1 & 48hpf & & & \\
\hline$f b \ln 2$ & fibulin 2 & 48hpf & 96hpf & $8 \mathrm{dpf}$ & $15 \mathrm{dpf}$ \\
\hline plekhg 1 & pleckstrin homology and RhoGEF domain containing G1 & 48hpf & & & \\
\hline LOC107097201 & integrin alpha-D-like & & 96hpf & & \\
\hline \multicolumn{6}{|l|}{ Muscle } \\
\hline myo7a & myosin VIIA & 48hpf & & & \\
\hline LOC107097407 & myosin-7B-like & 48hpf & 96hpf & & \\
\hline LOC107087696 & myosin-11-like & & & $8 \mathrm{dpf}$ & \\
\hline \multicolumn{6}{|l|}{ Tgf-beta } \\
\hline tbrg 4 & transforming growth factor beta regulator 4 & 48hpf & & & \\
\hline \multicolumn{6}{|l|}{ Transciption Factor } \\
\hline $\operatorname{irx} 6$ & iroquois homeobox 6 & 48hpf & & & \\
\hline gata6 & GATA binding protein 6 & & & $8 \mathrm{dpf}$ & \\
\hline LOC107090297 & GATA zinc finger domain-containing protein 14-like & & & & $15 \mathrm{dpf}$ \\
\hline \multicolumn{6}{|l|}{ Wnt } \\
\hline$f z d g$ & frizzled class receptor 9 & 48hpf & & & \\
\hline$w n t 2 b$ & wingless-type MMTV integration site family member $2 \mathrm{~B}$ & 48hpf & & & \\
\hline LOC107090002 & dixin-A-like & & 96hpf & $8 \mathrm{dpf}$ & \\
\hline LOC107098026 & dickkopf-related protein 3-like & & & & $15 \mathrm{dpf}$ \\
\hline \multicolumn{6}{|l|}{ Other } \\
\hline LOC107101384 & adipocyte plasma membrane-associated protein-like & 48hpf & & & \\
\hline clptm1 & cleft lip and palate associated transmembrane protein 1 & 48hpf & & & \\
\hline fkbp2 & FK506 binding protein 2 & 48hpf & & & \\
\hline foxj3 & forkhead box J3 & 48hpf & & & \\
\hline oraov1 & oral cancer overexpressed 1 & 48hpf & & $8 \mathrm{dpf}$ & $15 \mathrm{dpf}$ \\
\hline smarcd2 & $\begin{array}{l}\text { SWI/SNF related, matrix associated, actin dependent } \\
\text { regulator of chromatin, subfamily d, member } 2\end{array}$ & 48hpf & & & \\
\hline LOC107105123 & syndecan-2-like & 48hpf & & & \\
\hline LOC107087936 & transcription regulator protein $\mathrm{BACH} 1$-like & & 96hpf & & \\
\hline LOC107083667 & alkaline phosphatase-like & & & $8 \mathrm{dpf}$ & \\
\hline setd6 & SET domain containing 6 & 48hpf & 96hpf & $8 \mathrm{dpf}$ & $15 \mathrm{dpf}$ \\
\hline ptgr2 & prostaglandin reductase 2 & & & & $15 \mathrm{dpf}$ \\
\hline LOC107094401 & kallikrein-7-like & & & & $15 \mathrm{dpf}$ \\
\hline
\end{tabular}

Shown are pupfish gene names with zebrafish gene names in parentheses

activated, or that RNA-seq is not sensitive enough to pick up differential expression in each of these genes.

\section{Discussion}

This paper presents foundational data as a first step towards addressing the fundamental question of how phenotypic variation is produced during the early stages of diversification, here among three closely related species. We use RNA-seq to study gene expression divergence associated with ecological and morphological diversification in three species of Cyprinodon pupfishes that are estimated to have diverged in only the last 
Table 6 Select genes from all four intersection sets that are overexpressed in the durophage

\begin{tabular}{|c|c|c|c|c|c|}
\hline \multirow{2}{*}{$\frac{\text { Gene Group }}{\text { Apoptosis }}$} & \multirow[t]{2}{*}{ Gene Name } & \multicolumn{3}{|c|}{ Intersection Set } & \\
\hline & & & & & \\
\hline LOC107095016 (aifm4) & apoptosis-inducing factor 3-like & $48 \mathrm{hpf}$ & 96hpf & $8 \mathrm{dpf}$ & $15 \mathrm{dpf}$ \\
\hline LOC107104525 & apoptosis-stimulating of p53 protein 2-like & & & $8 \mathrm{dpf}$ & \\
\hline bag1 & BCL2 associated athanogene 1 & 48hpf & & & \\
\hline LOC107103519 & caspase recruitment domain-containing protein 8-like & & & & $15 \mathrm{dpf}$ \\
\hline \multicolumn{6}{|l|}{ Calcium Signaling } \\
\hline anxa1 & annexin $\mathrm{A} 1$ & $48 \mathrm{hpf}$ & & & \\
\hline capn3 & calpain 3 & 48hpf & & & \\
\hline capn5 & calpain 5 & $48 \mathrm{hpf}$ & & & \\
\hline \multicolumn{6}{|l|}{ Cell Adhesion } \\
\hline LOC107095872 (cdh4) & cadherin-4-like & $48 \mathrm{hpf}$ & & & \\
\hline LOC107093297 & claudin-4-like & 96hpf & & & \\
\hline \multicolumn{6}{|l|}{ Cytokine/Chemokine } \\
\hline tnfaip3 & TNF alpha induced protein 3 & 48hpf & 96hpf & $8 \mathrm{dpf}$ & \\
\hline \multicolumn{6}{|l|}{ Chaperone/Heat Shock } \\
\hline dnajc27 & $\mathrm{Hsp} 40$ & $48 \mathrm{hpf}$ & & $8 \mathrm{dpf}$ & \\
\hline LOC107099519 (dnajc11) & dnaJ homolog subfamily C member 11-like & $48 \mathrm{hpf}$ & & & \\
\hline \multicolumn{6}{|l|}{ Growth Factor } \\
\hline LOC107091872 (epha4b) & ephrin type-A receptor 3-like & $48 \mathrm{hpf}$ & & & \\
\hline LOC107090696 & ephrin type-B receptor 2-like & 48hpf & & & \\
\hline LOC107086153 & platelet-derived growth factor receptor-like protein & & & $8 \mathrm{dpf}$ & \\
\hline \multicolumn{6}{|l|}{ Extracellular Matrix } \\
\hline LOC107102808 & integrin beta-2-like & $48 \mathrm{hpf}$ & & & \\
\hline LOC107088257 & integumentary mucin A.1-like & 48hpf & & & \\
\hline col16al & collagen, type XVI, alpha 1 & & & $8 \mathrm{dpf}$ & \\
\hline thsd1 & thrombospondin type 1 domain containing 1 & & 96hpf & & \\
\hline LOC107083667 & alkaline phosphatase-like & & & & $15 \mathrm{dpf}$ \\
\hline \multicolumn{6}{|l|}{ Muscle } \\
\hline myoz3 & myozenin3 & & & & $15 \mathrm{dpf}$ \\
\hline \multicolumn{6}{|l|}{ Transcription Factors } \\
\hline atoh8 & atonal bHLH transcription factor 8 & $48 \mathrm{hpf}$ & & & \\
\hline gatad2b & GATA zinc finger domain containing 2B & 48hpf & & & \\
\hline ncoar & nuclear receptor coactivator 1 & $48 \mathrm{hpf}$ & 96hpf & $8 \mathrm{dpf}$ & \\
\hline LOC107081391 & nuclear receptor coactivator 1-like & 48hpf & 96hpf & $8 \mathrm{dpf}$ & $15 \mathrm{dpf}$ \\
\hline $\operatorname{six} 1$ & SIX homeobox 1 & $48 \mathrm{hpf}$ & & & \\
\hline six4 & SIX homeobox 4 & 48hpf & & & \\
\hline \multicolumn{6}{|l|}{ Other } \\
\hline LOC107098473 & von Willebrand factor A domain-containing protein 7-like & $48 \mathrm{hpf}$ & & & \\
\hline LOC107084756 & toll-like receptor 2 type-2 & & & & $15 \mathrm{dpf}$ \\
\hline
\end{tabular}

Shown are pupfish gene names with zebrafish gene names in parentheses

$6000-10,000$ years $[12,35]$. RNA-seq reveals the amount of mRNA transcription, and may detect both changes to spatial location of genes as well as altered onset or offset of expression across species.
Gene expression divergence is known to accumulate with time since common ancestry [71-73]. Even at the shallow divergence time studied here, patterns of gene expression divergence appear to reflect phylogenetic 
Table 7 Select genes from all four intersection sets that are underexpressed in the durophage

\begin{tabular}{|c|c|c|c|c|c|}
\hline \multirow{2}{*}{$\begin{array}{l}\text { Gene Group } \\
\text { Apoptosis }\end{array}$} & \multirow[t]{2}{*}{ Gene Name } & \multicolumn{3}{|c|}{ Intersection Set } & \\
\hline & & & & & \\
\hline bag2 & BCL2 associated athanogene 2 & $48 \mathrm{hpf}$ & & & \\
\hline LOC107082055 (casp8/2) & caspase-8-like & $48 \mathrm{hpf}$ & & & \\
\hline \multicolumn{6}{|l|}{ Bardet-Biedl syndrome } \\
\hline$b b s 12$ & Bardet-Biedl syndrome 12 & $48 \mathrm{hpf}$ & $96 \mathrm{hpf}$ & & \\
\hline \multicolumn{6}{|l|}{ Calcium Signaling } \\
\hline anxa10 & annexin $\mathrm{A} 10$ & $48 \mathrm{hpf}$ & & & \\
\hline LOC107089898 (camkk1a) & calcium/calmodulin-dependent protein kinase kinase 1-like & & $96 \mathrm{hpf}$ & & $15 \mathrm{dpf}$ \\
\hline \multicolumn{6}{|l|}{ Cell Adhesion } \\
\hline$c d 302$ & CD302 molecule & $48 \mathrm{hpf}$ & $96 \mathrm{hpf}$ & & \\
\hline LOC107104323 (bub1) & mitotic checkpoint serine/threonine-protein kinase BUB1-like & $48 \mathrm{hpf}$ & & & \\
\hline LOC107097627 & protocadherin beta-16-like & & $96 \mathrm{hpf}$ & & \\
\hline LOC107100986 (pcdh10b) & protocadherin-10-like & & $96 \mathrm{hpf}$ & & \\
\hline LOC107105174 & cell adhesion molecule 2-like & & & $8 \mathrm{dpf}$ & \\
\hline \multicolumn{6}{|l|}{ Cell Cycle } \\
\hline LOC107092486 (aunip) & aurora kinase $A$ and ninein-interacting protein-like & $48 \mathrm{hpf}$ & & & \\
\hline $\operatorname{cdc} 20$ & cell division cycle 20 & $48 \mathrm{hpf}$ & & & \\
\hline cdca7l & cell division cycle associated 7-like & $48 \mathrm{hpf}$ & $96 \mathrm{hpf}$ & & \\
\hline \multicolumn{6}{|l|}{ Cytokine/Chemokine } \\
\hline LOC107085925 & C-C motif chemokine 25-like & $48 \mathrm{hpf}$ & & & \\
\hline traf4 & TNF receptor associated factor 4 & & $96 \mathrm{hpf}$ & & \\
\hline LOC107095001 (csfira) & macrophage colony-stimulating factor 1 receptor 1 -like & & & $8 \mathrm{dpf}$ & \\
\hline LOC107090375 (csf1b) & uncharacterized (macrophage colony stimulating factor 1b) & & $96 \mathrm{hpf}$ & & \\
\hline \multicolumn{6}{|l|}{ Chaperone/Heat Shock } \\
\hline LOC107086201 & heat shock $70 \mathrm{kDa}$ protein 12A-like & $48 \mathrm{hpf}$ & & & \\
\hline \multicolumn{6}{|l|}{ Growth Factor } \\
\hline LOC107082400 & endothelin B receptor-like & $48 \mathrm{hpf}$ & & & \\
\hline LOC107086153 & platelet-derived growth factor receptor-like protein & $48 \mathrm{hpf}$ & & & \\
\hline flt 1 & fms-related tyrosine kinase 1 & & $96 \mathrm{hpf}$ & & \\
\hline \multicolumn{6}{|l|}{ IFG signaling } \\
\hline LOC107082691 (igfbp7) & insulin-like growth factor-binding protein 7 & & $96 \mathrm{hpf}$ & & \\
\hline \multicolumn{6}{|l|}{ Matrix } \\
\hline LOC107101414 & FRAS1-related extracellular matrix protein 2-like & $48 \mathrm{hpf}$ & & & \\
\hline LOC107103703 & FRAS1-related extracellular matrix protein 2-like & $48 \mathrm{hpf}$ & & & \\
\hline LOC107094308 & integrin beta-1-like & $48 \mathrm{hpf}$ & & & \\
\hline pcolce2 & procollagen C-endopeptidase enhancer 2 & $48 \mathrm{hpf}$ & & & \\
\hline otol1 & otolin 1 & & $96 \mathrm{hpf}$ & $8 \mathrm{dpf}$ & \\
\hline \multicolumn{6}{|l|}{ Muscle } \\
\hline LOC107103762 (mybpha) & myosin-binding protein $\mathrm{H}$-like & & & $8 \mathrm{dpf}$ & $15 \mathrm{dpf}$ \\
\hline \multicolumn{6}{|l|}{ BMP/Tgf-beta } \\
\hline twsgl & twisted gastrulation BMP signaling modulator 1 & $48 \mathrm{hpf}$ & & & \\
\hline \multicolumn{6}{|l|}{ Transciption Factors } \\
\hline$d b \times 2$ & developing brain homeobox 2 & $48 \mathrm{hpf}$ & & & \\
\hline hes3 & hes family bHLH transcription factor 3 & $48 \mathrm{hpf}$ & & & \\
\hline
\end{tabular}


Table 7 Select genes from all four intersection sets that are underexpressed in the durophage (Continued)

\begin{tabular}{|c|c|c|c|c|}
\hline sall4 & spalt-like transcription factor 4 & $48 \mathrm{hpf}$ & & \\
\hline \multicolumn{5}{|l|}{ Wnt } \\
\hline LOC107099028 (tmem88b) & transmembrane protein 88-like & $48 \mathrm{hpf}$ & & \\
\hline wnt1 & wingless-type MMTV integration site family member 1 & $48 \mathrm{hpf}$ & & \\
\hline wnt10b & wingless-type MMTV integration site family member $10 \mathrm{~b}$ & $48 \mathrm{hpf}$ & & \\
\hline \multicolumn{5}{|l|}{ Other } \\
\hline sipa1/3 & signal-induced proliferation-associated 1 like 3 & $48 \mathrm{hpf}$ & 8dpf & \\
\hline tfpi2 & tissue factor pathway inhibitor 2 & $48 \mathrm{hpf}$ & & \\
\hline LOC107100889 & myeloid-associated differentiation marker homolog & & 8dpf & \\
\hline LOC107104594 & TRPM8 channel-associated factor homolog & & 8dpf & \\
\hline mos & v-mos Moloney murine sarcoma viral oncogene homolog & & & $15 \mathrm{dpf}$ \\
\hline
\end{tabular}

estimates of time since common ancestry, at least partially. Our data support other studies placing the marine omnivore population as the sister group to a clade of San Salvador pupfishes [31, 39], suggesting that the durophage and scale-biter species evolved from one or multiple inland omnivore population(s) present in the salt water lakes of San Salvador Island. We find that the marine omnivore differs from the inland taxa by a single $\mathrm{PC}$ axis at each stage, possibly reflecting the divergence of the inland forms following colonization of San Salvador by the marine lineage. Interestingly, in contrast to an expected scenario where morphologically similar omnivore populations are also most similar in gene expression patterns, principal component analyses of gene expression variance grouped the inland omnivore with the endemic inland durophage rather than the morphologically similar marine omnivore. This unexpected result could reflect time since common ancestry or ongoing introgression among these two taxa [31, 39] or both.

Gene set enrichment analysis suggested that a number of conserved cellular processes may be differentially regulated among species of pupfishes including Wnt signaling, hedgehog signaling, myogenesis, adipogenesis, the inflammation response, and fatty acid metabolism. Many of the gene sets identified as enriched are related to cell cycle regulation, perhaps indicating differences in rates of cell proliferation among species. Of particular note was enrichment for targets of Myc transcription factor activity. Myc is an immediate early response transcription factor that among other roles mediates a cellular response to growth factors. Previous work on transcriptional responses to diet in cichlid fishes and bone loading in mouse have both implicated gene expression modifications to immediate early response genes $[61,74]$.

GSEA suggested that the expression of genes functioning in the epithelial to mesenchymal transition, as well as the estrogen response, may be differentially modified in pupfish species. Both craniofacial morphology and pigmentation differ among pupfish species, and both of these traits are derived from neural crest cells that undergo an epithelial to mesenchymal transition prior to migration. Estrogen signaling is known to affect bone and has been shown to underlie skull sexual dimorphism in Anolis carolinensis [75].

\section{Identification of genes of interest}

To identify specific genes of interest, we focused on the intersection sets of genes differentially expressed in all three comparisons to either the durophage or scale-biter, the two species with extreme morphologies. The rationale for this approach is that if a set of genes is differentially expressed in all three comparisons with an extreme phenotype, these expression differences are likely to be biologically meaningful.

Genes identified by intersection sets were typically over or underexpressed in only a single taxon (Additional file 16: Figure S9). While we cannot rule out that jaw morphological differences among these species of pupfishes are produced by fine-tuning the activity of the same upstream regulators, if this were the case we would have expected to see extensive sharing of differential expression of downstream target genes. It is intriguing to consider that differences appearing as opposite ends of a morphological spectrum (e.g. short jaws vs. long jaws) may be produced by tweaking different aspects of a jaw developmental program.

Our study compares closely related wild taxa, diverged as recently as 10,000 years. As such, we would not expect large-fold differential gene expression and we are keenly aware that subtle changes in gene expression can have significant phenotypic consequences. For instance, small changes to the quantitative amount of Shh expression in the developing head of chickens has substantive phenotypic consequences for craniofacial morphology [9, 63]. Evolution operates by tinkering with existing genetic/developmental 


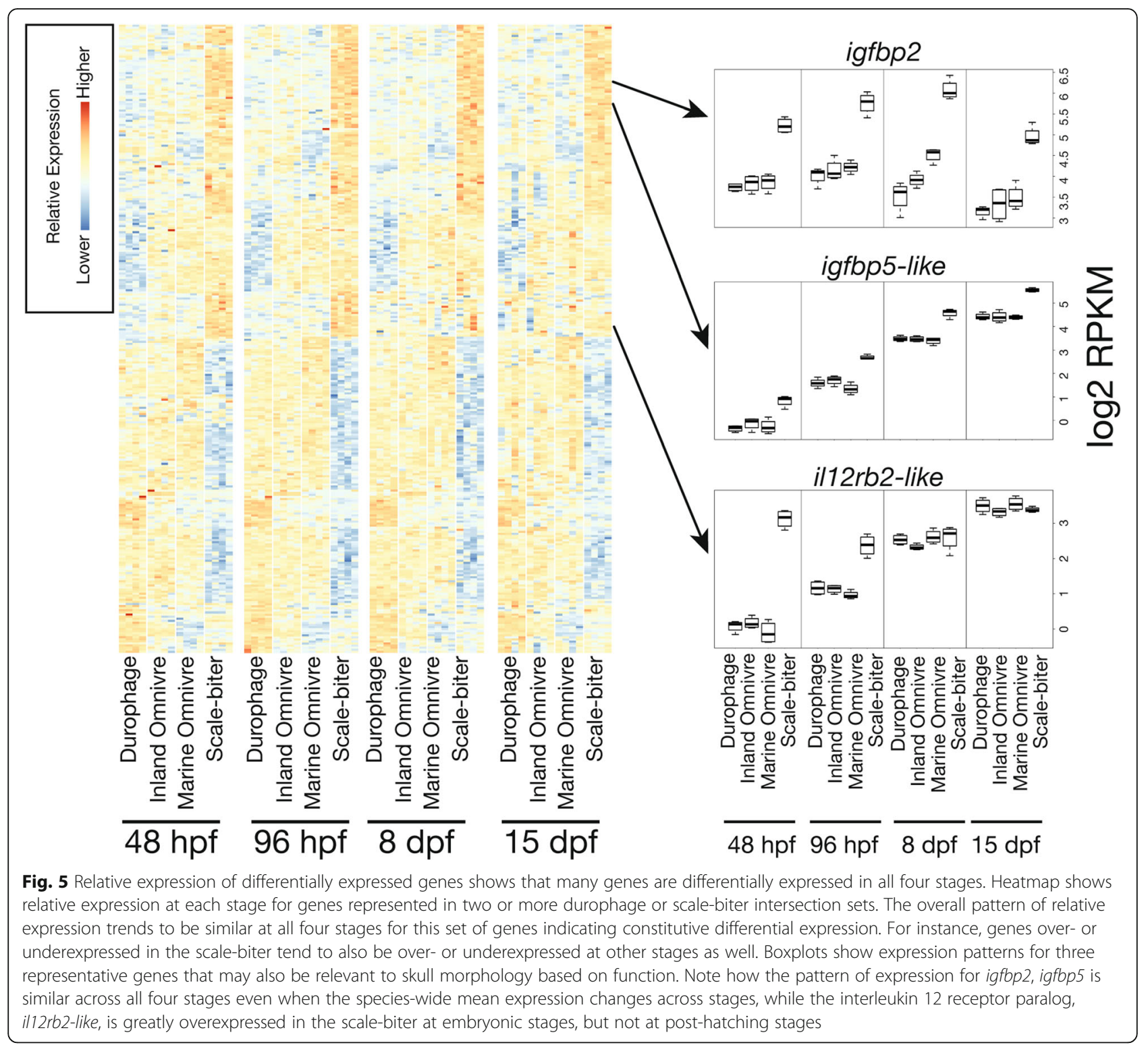

processes, and the striking morphological differences among species of pupfishes may be produced by slight modifications to gene expression. Despite a number of RNA-seq or microarray studies on closely related species there is still no expectation for the magnitude of biologically relevant gene expression divergence between species. An RNA-seq study of cichlid pharyngeal jaws found modest expression changes among morphs within the range of what we find among species of pupfishes [74]. Rather than arbitrarily discarding everything except the most dramatically over or underexpressed genes, we opted to use a lower threshold of differential expression but leveraged the fact that we have three comparisons for each focal taxon in order to limit our set of DE genes to those most likely to be biologically meaningful.
We applied a $\log 20.2$ fold change threshold to label genes as $\mathrm{DE}$, in contrast to many other gene expression studies targeting larger expression differences among treatments by using a 1.5- or 2-fold change threshold to identify genes of interest. Applying this higher threshold to our data does not substantially change our conclusions (Additional file 17: Table S8, Additional file 18: Table S9, Additional file 19: Table S10, Additional file 20: Table S11, Additional file 21: Table S12, Additional file 22: Table S13, Additional file 23: Table S14 and Additional file 24: Table S15). However, using the higher threshold, wnt ligands would not have been identified (wnt ligands were DE by $1.2-1.48$ fold in any pairwise comparison). Additionally, a number of genes in the intersection sets would be excluded with a higher threshold simply because a single 


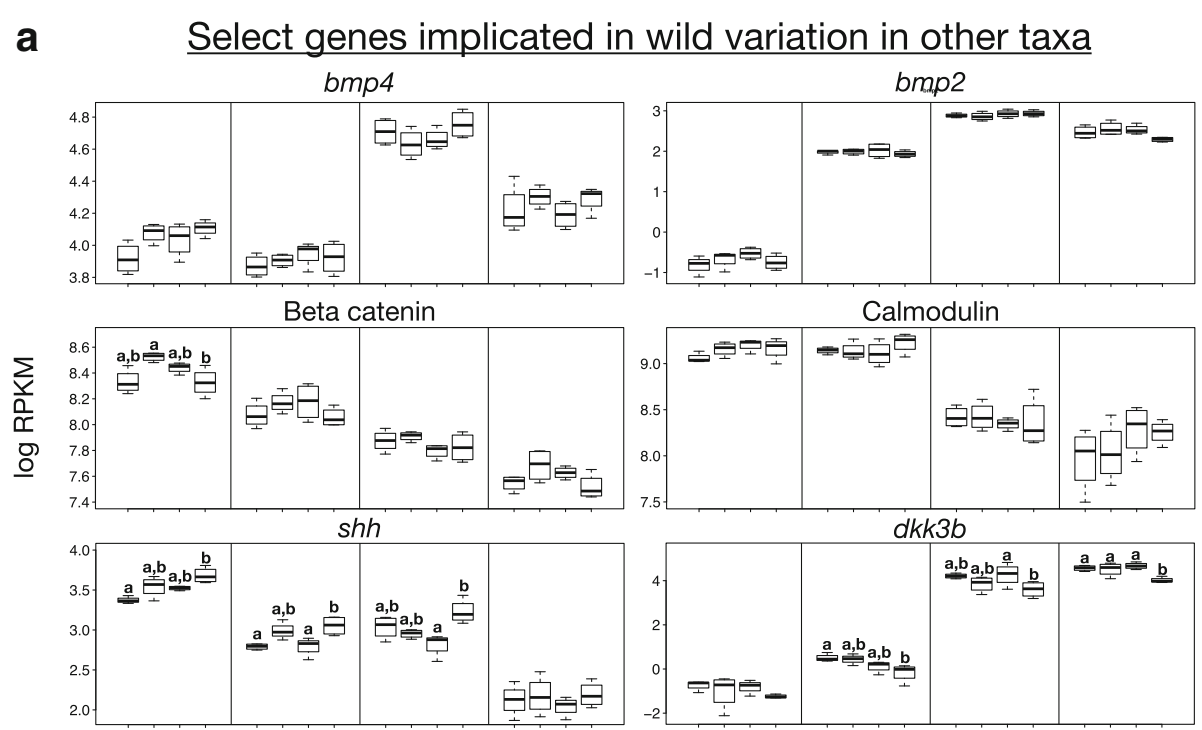

b

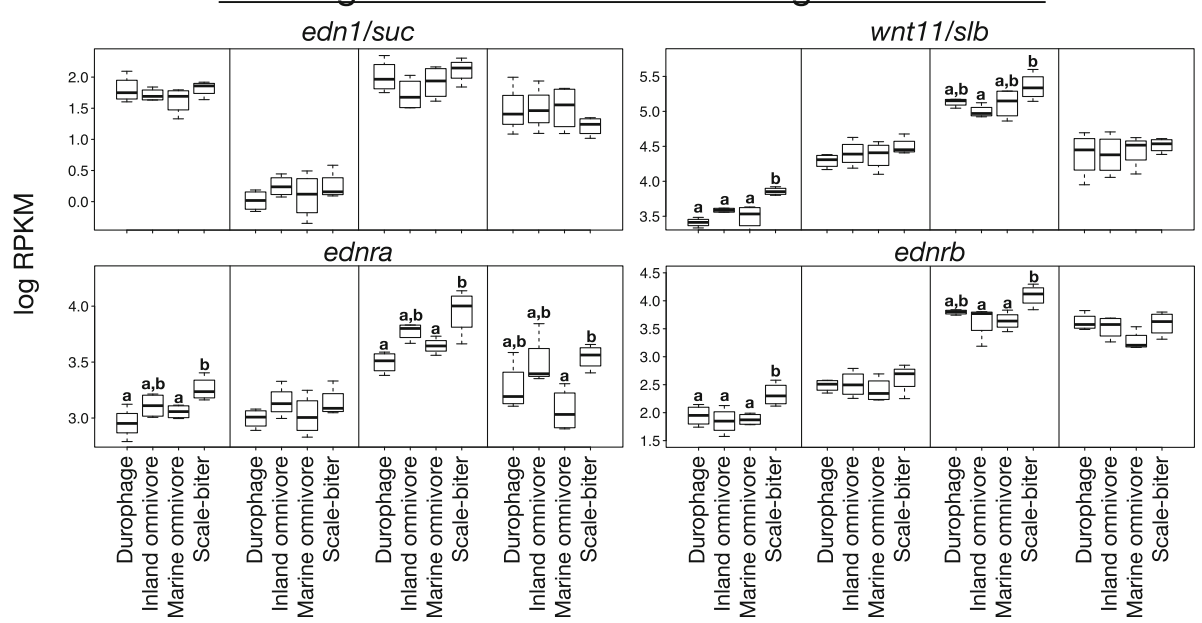

Fig. 6 Expression of several candidate genes associated with jaw morphological diversification in other taxa (a) or identified as affecting jaw and cranial morphology from a zebrafish mutagenesis screen (b). a Boxplots of gene expression levels for each species at all four stages of development. Gene expression values were measured as log2 transformed reads per kilobase per million reads (RPKM) for a set of candidate genes known to affect skull or cranial morphology in other wild vertebrates. These genes are not differentially expressed among different species of pupfish, with the exception of shh that tends to be slightly overexpressed in the scale-biter, and $d k k 3 b$ which is underexpressed in the scale-biter. $\mathbf{b}$ Expression of four genes identified from a zebrafish mutagenesis screen that may contribute to jaw morphological differences among species of pupfish. Note that while edn 1 is not differentially expressed, two endothelin receptors are. Letters indicate significant differential expression (FDR $\leq 0.1$ ) in pairwise comparisons at each stage. Letters are omitted from stages where no pairwise comparisons are significant

comparison was slightly below the threshold, although even at the higher threshold, the two other comparisons categorized them as DE. Requiring genes to be $\mathrm{DE}$ in all three comparisons, even with a lower threshold, is already a stringent criterion. A threshold of 1.5 or 2 fold is arbitrary, but detecting a difference in all three comparisons suggests biological meaning.

While the main focus of our project was to identify genes differentially expressed among species of pupfishes, our data are also interesting for those genes not differentially expressed. Genes, such as Bmp4 and calmodulin, which are thought to be key determinants of jaw morphology in African cichlids and Galapagos finches are notably not differentially expressed in pupfishes with distinctive jaw phenotypes (Fig. 6). While it is very possible that these genes could be differentially expressed at time points not sampled, our data suggest that the sources of skull diversity in pupfishes differs from what has been shown for these other vertebrate taxa. We 

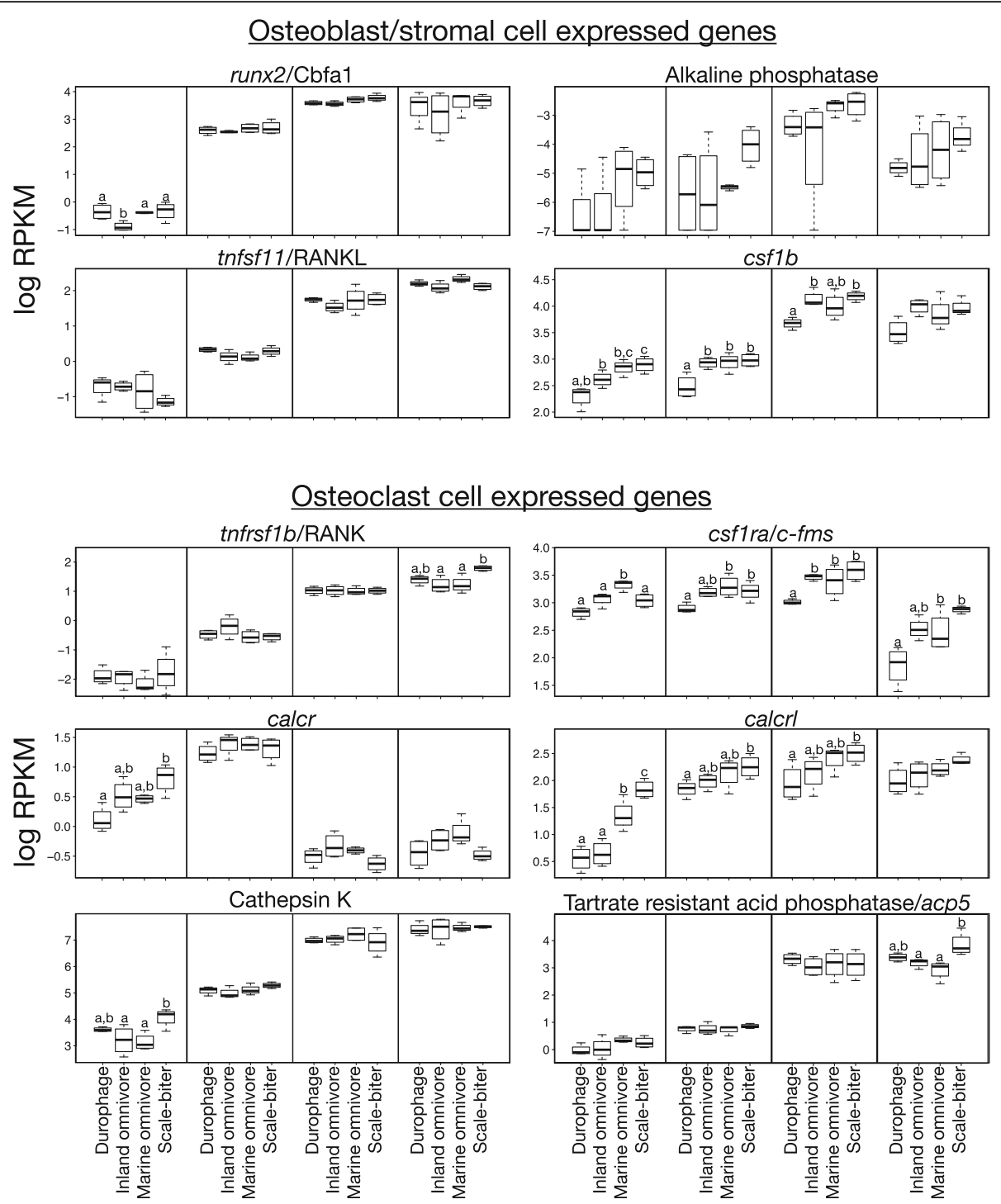

Fig. 7 Expression of genes commonly used as molecular markers of osteoblast and osteoclast cells indicate that genes functioning in osteoblast differentiation are typically not differentially expressed among species of pupfish, while a number of osteoclast expressed genes tend to be overexpressed in the scale-biter and underexpressed in the durophage. Gene expression values were measured as log2 transformed RPKM similar to Fig. 6. Letters indicate significant differential expression (FDR $\leq 0.1)$ in pairwise comparisons at each stage. Letters are omitted from stages where no pairwise comparisons are significant

cannot rule out the possibility that RNA-seq is either not sensitive enough to pick up a very slight change in the expression of these genes, or that these genes are post-transcriptionally modified.

Among the genes that were identified by RNA-seq as possibly related to jaw diversification in pupfishes are several that code for molecules functioning in growth factor signaling and cytokine signaling. These functional groups are particularly interesting because they point to genes of interest as well as possible cellular-developmental processes underlying the origins of jaw morphological diversity. Below we outline three hypotheses that emerge from our RNA-seq data.

\section{Wnt signaling}

We found multiple wht ligands to be differentially expressed among pupfish taxa at $48 \mathrm{hpf}$. We note that these genes would not have been identified had we applied a 1.5 fold change threshold, though GSEA analysis did identify enrichment of Wnt signaling in some comparisons. At $48 \mathrm{hpf}$, neural crest cells contributing to jaw development are relatively undifferentiated and aggregated in the pharyngeal pouches of the pupfish head. After this stage, embryos experience a period of rapid growth and formation of cranial cartilages.

Wnt signaling plays an established role in bone development, regulating the growth, differentiation, and functioning 
of bone remodeling cells such as osteoblasts [54, 76]. Modifications to Wnt signaling have been shown to affect bone mass and homeostasis in general [76], and to affect craniofacial development in particular [25-27, 29, 51, 77]. Chief among genes we identified as overexpressed in the scalebiter is wnt11, which is identified as the gene affected in zebrafish silberblick mutants [51]. Zebrafish lacking functional Wnt11 show dramatic reductions to the anterior skull elements, the same bony skull elements most different among species of pupfishes. Interestingly, the phenotypic effect of the Wnt11 gene in zebrafish is modified by the transmembrane protein Tmem88 [78]. Zebrafish double morpholino knockdowns targeting both wnt11 and tmem 88 expression have more extreme phenotypes. In pupfishes, tmem88 is underexpressed in the durophage at the same stage that wnt11 is overexpressed in the scale-biter.

Wnt signaling has been shown to be associated with jaw diversification in African cichlids [26, 79], with the evolution of a fused maxilla in the bird beak [27], and with the specification and morphogenesis of jaw structures in mice [25, 77]. Thus Wnt signaling is emerging as an important source of craniofacial variation in wild taxa. With the exception of wnt2b, Wnt ligands were consistently overexpressed in the scale-biter and underexpressed in the durophage (Fig. 4). This raises the hypothesis of whether Wnt signaling is differentially regulated in the scale-biter and durophage taxa at early embryonic stages, a result further supported by GSEA results. That we find multiple Wnt ligands all differentially expressed at the same stage suggests that a process upstream of Wnt may be differentially regulated. Hedgehog signaling often regulates and is co-regulated by Wnt ligand production in other systems, and is thus an obvious candidate. In the head, Wnt signaling is known to interact with a frontal nasal cell proliferative zone (FEZ) marked by adjacent $s h h / f g f 8$ expression domains $[15,27$, 80]. Thus multiple avenues are available for future work experimentally manipulating Wnt ligands and exploring how Wnt interactions with $s h h / f g f 8$ expression are modified (or not) among species of pupfishes.

\section{Insulin-like growth factor signaling}

Insulin-like growth factors (IGF-1 and IGF-2) are two of the most abundant growth factors in bone, inducing a number of transcriptional responses in myoblasts, chondrocytes, and osteoblasts that affect cellular differentiation, activity, and rates of bone deposition and homeostasis [54, 81]. IGF-1 has been associated with variation in dog breed size [82], but a function for IGF-1 signaling in skull formation is less well understood (though see $[83,84]$ ). In the extracellular matrix, Igf proteins bind to Igf binding proteins, and the cellular responses to Igf proteins are strongly dependent on the presence of different
Igf binding proteins [54]. We found two binding proteins, igfbp 2 and igfbp5-like (most probably one of two igfbp5 paralogs), to be greatly overexpressed in the scale-biter at all stages. Transcript abundance of igfbp 2 in the scale-biter was more than 2-fold that of other species indicating substantial up-regulation and both genes would have been identified with a higher DE threshold, highlighting the extreme overexpression of these genes in the scale-biter. Further supporting a potential role for Igf signaling is that GSEA identified enrichment of Igf signaling in genes overexpressed in the scale-biter (Additional file 9: Table S6). The effects of Igf binding proteins on bone growth and homeostasis are typically complex and depend on numerous factors [54]. In mammalian systems igfbp 2 has been associated with both negative regulation of bone mass $[85,86]$ and positive stimulation of osteoblast differentiation and activity [87], while igfbp5 has typically been associated with increased bone deposition [54]. Interestingly, we also find a number of genes related to metabolism and lipid transport that would be concordant with altered cellular responses in response to modified Igf signaling among species. Given the critical role Igf signaling plays in bone development and remodeling, and the dramatic overexpression of these two Igf binding proteins in the scale-biter, this is an obvious candidate for further study.

\section{Cytokine and Chemokine signaling}

Our observation that multiple cytokine/chemokine-related signaling molecules are differentially expressed among species of pupfishes is interesting because it provides a potential link between the cellular inflammation response and bone homeostasis such as occurs during pathologies like osteoporosis [88]. In our dataset, genes linked to inflammation included tumor necrosis factor family members, cytokines, interleukins and other immune cell stimulatory molecules, as well as inflammation activated intracellular molecules such as a number of Nod-like receptor paralogs (Tables 1, 2, 3 and 4; Additional file 1: Tables S2-S26).

In addition to roles in immune function and inflammation, cytokine signaling plays a critical role during non-pathological bone homeostasis [54]. Tumor necrosis factor and interleukin molecules mediate signaling among osteoblasts and osteoclasts, and play established roles affecting osteoclast differentiation and functioning $[54,88,89]$. We found many cytokine genes to be DE at 48 and $96 \mathrm{hpf}$, prior to bone formation, perhaps suggesting modifications to osteoclast differentiation. Our data further showed that a number of genes expressed by osteoclasts including calcitonin receptors (calcr and calcrl) and tartrate resistant acid phosphatase (acp5) tended to 
be overexpressed in the scale-biter further lending support to the idea that either osteoclast number or functioning may vary among species of pupfishes. The central role osteoclasts play in bone remodeling makes this an intriguing new avenue for research.

Studies of transcriptomic responses to bone loading following exercise have also implicated a dominant role for cytokine signaling in bone homeostasis $[61,74,90]$. Many of the genes identified as differentially expressed in our dataset are orthologs and gene family members of genes that have also been found to be differentially expressed in the pharyngeal jaws of adult cichlid fishes feeding on hard-shelled prey or soft food, and in the bones of adult mice undergoing bone remodeling following exercise [61, 74, 91]. Thus, differential expression of a number of cytokine signaling genes among pupfishes might suggest a connection between the cellular mechanisms of developmental plasticity and the cellular mechanisms underlying evolutionary divergence.

\section{Constitutive differential expression of genes}

Careful consideration of developmental stage is commonly believed to be critical for identifying modifications to gene expression associated with phenotypic change. This can provide a dilemma for researchers deciding how fine to sample across development (a concern especially relevant to research on non-model genetic organisms since samples are often relatively labor intensive to obtain). An alternative model considers that once a gene is expressed in an organ, it may continue to be expressed in that organ for a long period of time (e.g. constitutive expression). We investigated this by identifying genes $\mathrm{DE}$ at more than one stage and found that while approximately $80 \%$ of the genes in the intersection sets were $\mathrm{DE}$ at only a single stage, a sizeable percentage of genes $(\sim 20 \%)$ tended towards being over- or under-expressed in either the scalebiter or durophage at multiple stages (Fig. 6).

Periods between our sampling stages were as few as two days and as much as a week. We reasoned, therefore, that when a gene was differentially expressed at more than one stage, this was good evidence that that gene was differentially expressed among species for a long block of time. We refer to these genes as constitutively differentially expressed genes since they followed a pattern of being over- or underexpressed among species through embryogenesis and juvenile growth. The presence of these constitutively DE genes would suggest that in some instances fine sampling of developmental time may be unnecessary to identify a non-negligible percentage of genes as DE. Furthermore, the true percentage of constitutively differentially expressed genes is almost certainly higher than what we report here since we highlight in this paper patterns from only those genes that appeared in two or more of our intersection sets, but we noted that many additional genes also showed this pattern of constitutive expression in our dataset. We suspect that this pattern of constitutive differential expression may be a dominant pattern for many of the genes identified by us to be differentially expressed among closely related pupfish taxa.

We want to stress that while many genes appear to be constitutively differentially expressed, a much greater percentage $(\sim 80 \%)$ of genes were DE at only 1 or 2 stages. Gene expression is known to be dynamic during embryonic development when body plans and organs are being patterned. Thus different classes of genes may be more or less likely to be constitutively differentially expressed, and some genes, DE at only a single stage, may be evolutionarily important.

\section{Other traits}

The pupfishes in this study differ not only in jaw morphology, but also traits such as behavior and coloration $[12,13,92,93]$. Undoubtedly some of the transcriptional differences that we identified are related to these and other traits. For example, GSEA identified enrichment of neuronal pathways at embryonic stages (and presumptive brain tissue was necessarily included in these early embryonic samples) highlighting to us that not every expression difference we identify is related to jaw morphology. Determining which genes are related to jaw morphology, however, is complicated by interactions among different tissues. For instance, signaling centers located in the developing brain are known to play a role in craniofacial development [16].

As a further example, the inland species differ dramatically in coloration in both wild and laboratory conditions. Adult male scale-biters are uniformly black, while durophage males and females have a milky white body coloration. Vertebrate jaws and pigment cells both develop from migratory neural crest cells, and two genes differentially expressed in our data, endothelin receptor $\mathrm{b}(e d n r b)$ and macrophage colony stimulating factor 1 (csflb), are implicated to affect both jaw/bone development and melanophore number in zebrafish $[59,94]$. All three pupfishes have melanophore cells (black) and leucophore cells (white), but whether these coloration differences result from changes to cell number, distribution, or by some other mechanism is unknown. These same genes may or may not play a role in color differences among species of pupfishes (or jaws for that matter); we mention these only to emphasize that some transcriptional variation in our dataset may affect traits other than jaws or have pleiotropic effects on multiple traits that differ among pupfishes. 


\section{Conclusions}

We used RNA-seq to identify differentially expressed genes that may affect jaw development in pupfishes. Our data indicated that a number of molecules related to cell proliferation and differentiation, growth, bone development, and craniofacial form were differentially expressed prior to the appearance of morphological differences among species. In particular we identified a number of growth factor genes that are strong candidates for future research into the origins of jaw diversity in this group.

Our findings are concordant with recent work in birds, fishes, and mammals that have shown diverse mechanisms contributing to skull variation in different clades $[11,19,20,26-28,95]$. For complex traits such as skull morphology, what we really want to know is how the evolutionary tinkering of conserved developmental processes can produce macroevolutionary patterns of phenotypic diversity. Our data have identified a number of genes that play roles in modifying conserved developmental processes during skull development. Future work linking modifications of gene expression as shown here with changes in cellular-developmental processes such as cell proliferation, apoptosis, and differentiation will provide further insight into how a complex trait such as the vertebrate skull is modified during the early stages of speciation and ecological differentiation.

\section{Additional files}

\section{Additional file 1: Table S1. Includes STAR read mapping statistics.} (DOCX $131 \mathrm{~kb}$ )

Additional file 2: Figure S1. Phylogenetic relationships among San Salvador Island Cyprinodon taxa. Shown are maximum likelihood phylogenies built using RAXML under either a k-means partitioning scheme implemented by Partition Finder or a single partition scheme [49], and by applying either a GTRGAMMA or GTRCAT model. Note the general overall congruence across trees built using different assumptions, and that in each case the ML tree identifies the marine omnivore as and outgroup to a monophyletic San Salvador clade. (PDF $115 \mathrm{~kb}$ )

Additional file 3: Figure S2. Heatmap of sample by sample correlations (Pearson's r) shows both (1) dramatic differences in gene expression among stages and (2) that samples are highly correlated within each stage. Dendrogram represents hierarchical clustering tree of samples at all four stages based on log2 transformed RPKM gene expression values. Note the four major clusters corresponding to stage that appear as blocks of high correlation (red) in the heatmap. The dendrogram tips are colored by taxa showing that within each stage samples cluster by taxa. Durophage $=$ red, Inland omnivore $=$ blue, Marine omnivore $=$ green, Scale-biter $=$ purple. $($ PDF $2400 \mathrm{~kb})$

Additional file 4: Figure S3. Principal component plots show separation of taxa by gene expression along the first 3-4 PC axes. Shown are the first 3 (48 hpf) or 4 ( 96 hpf, 8 dpf, 15 dpf) PC axes for each stage. Note how different PC axes separate taxa. For instance at 96 hpf PC2 largely distinguishes the scale-biter samples from the other taxa, while PC4 largely distinguishes the durophage and inland omnivore samples. (PDF $175 \mathrm{~kb}$ )

Additional file 5: Table S2. GSEA results for Hallmark gene sets along PC axes at each stage. Excel table provides results from GSEA enrichment analysis for Hallmark gene sets along PC axes at each stage. Genes were pre-ranked by loadings on each axis prior to analysis. Human gene identifiers were used, and genes without an identifiable human ortholog were excluded from analysis. (XLS $98 \mathrm{~kb}$ )

Additional file 6: Table S3. GSEA results for Canonical Pathways gene sets along PC axes at each stage. Excel table provides results from GSEA enrichment analysis for Canonical Pathways gene sets along PC axes at each stage. Genes were pre-ranked by loadings on each axis prior to analysis. Human gene identifiers were used, and genes without an identifiable human ortholog were excluded from analysis. (XLS 552 kb)

Additional file 7: Table S4. GSEA results for Hallmark gene sets for genes over- or underexpressed in the scale-biter. Excel table provides results from GSEA enrichment analysis for Hallmark gene sets in genes differentially expressed in the scale-biter. Genes were pre-ranked by logFC in the scale-biter relative to all other taxa. Human gene identifiers were used, and genes without an identifiable human ortholog were excluded from analysis. (XLS $49 \mathrm{~kb}$ )

Additional file 8: Table S5. GSEA results for Hallmark gene sets for genes over- or underexpressed in the durophage. Excel table provides results from GSEA enrichment analysis for Hallmark gene sets in genes differentially expressed in the durophage. Genes were pre-ranked by $\log F C$ in the scale-biter relative to all other taxa. Human gene identifiers were used, and genes without an identifiable human ortholog were excluded from analysis. (XLS $49 \mathrm{~kb}$ )

Additional file 9: Table S6. GSEA results for Canonical Pathways gene sets for genes over- or underexpressed in the scale-biter. Excel table provides results from GSEA enrichment analysis for Canonical Pathways gene sets in genes differentially expressed in the scale-biter. Genes were pre-ranked by $\log F C$ in the scale-biter relative to all other taxa. Human gene identifiers were used, and genes without an identifiable human ortholog were excluded from analysis. (XLS $162 \mathrm{~kb}$ )

Additional file 10: Table S7. GSEA results for Canonical Pathways gene sets for genes over- or underexpressed in the durophage. Excel table provides results from GSEA enrichment analysis for Canonical Pathways gene sets in genes differentially expressed in the durophage. Genes were pre-ranked by $\log F C$ in the scale-biter relative to all other taxa. Human gene identifiers were used, and genes without an identifiable human ortholog were excluded from analysis. (XLS $105 \mathrm{~kb}$ )

Additional file 11: Figure S4. Identification of Intersection Sets. Venn diagrams showing the selection of intersection sets of genes differentially expressed in either the scale-biter ( $C$. desquamator) or durophage ( $C$. brontotheroides) at each stage. Numbers correspond to the number of genes in each set. Genes in the middle region are differentially expressed in all comparisons and are considered the intersection set of genes most likely to contribute to the derived skull morphology of the scale-biter and durophage respectively. (PDF $446 \mathrm{~kb}$ )

Additional file 12: Figure S5. Histograms of log2 fold change values for genes differentially expressed (FDR $\leq 0.1)$ at 48 hpf. Histograms of $\log 2$ fold change values for genes differentially expressed $(F D R \leq 0.1)$ at $48 \mathrm{hpf}$ in all pairwise comparisons. Most genes are differentially expressed by $1.2-1.5$ fold difference, with a much smaller number of genes DE by greater than 1.5 fold indicating a modest change to the magnitude at which most genes are DE. Insets highlight genes differentially expressed at log2 fold change less than 2. (PDF $271 \mathrm{~kb}$ )

Additional file 13: Figure S6. Histograms of log2 fold change values for genes differentially expressed (FDR $\leq 0.1)$ at 96 hpf. Histograms of log2 fold change values for genes differentially expressed $(F D R \leq 0.1)$ at $96 \mathrm{hpf}$ in all pairwise comparisons. Most genes are differentially expressed by 1.2-1.5 fold difference, with a much smaller number of genes DE by greater than 1.5 fold indicating a modest change to the magnitude at which most genes are DE. Insets highlight genes differentially expressed at log2 fold change less than 2. (PDF $273 \mathrm{~kb}$ )

Additional file 14: Figure S7. Histograms of log2 fold change values for genes differentially expressed (FDR $\leq 0.1$ ) at $8 \mathrm{dpf}$. Histograms of log2 fold change values for genes differentially expressed (FDR $\leq 0.1)$ at $8 \mathrm{dpf}$ 
in all pairwise comparisons. Most genes are differentially expressed by 1.2-1.5 fold difference, with a much smaller number of genes DE by greater than 1.5 fold indicating a modest change to the magnitude at which most genes are DE. But compare to embryonic stages $48 \mathrm{hpf}$ and 96 hpf there are many more genes DE by greater than 1.5 fold. Insets highlight genes differentially expressed at log2 fold change less than 2. (PDF $271 \mathrm{~kb}$ )

Additional file 15: Figure S8. Histograms of log2 fold change values for genes differentially expressed (FDR $\leq 0.1)$ at $15 \mathrm{dpf}$. Histograms of $\log 2$ fold change values for genes differentially expressed (FDR $\leq 0.1$ ) at $15 \mathrm{dpf}$ in all pairwise comparisons. Most genes are differentially expressed by 1.2-1.5 fold difference, with a much smaller number of genes DE by greater than 1.5 fold indicating a modest change to the magnitude at which most genes are DE. But compare to embryonic stages $48 \mathrm{hpf}$ and $96 \mathrm{hpf}$ there are many more genes DE by greater than 1.5 fold. Insets highlight genes differentially expressed at log2 fold change less than 2. (PDF $265 \mathrm{~kb}$ )

Additional file 16: Figure S9. Heatmap of genes in both the scale-biter and durophage intersection sets. Differentially expressed genes are over- or underexpressed in a single taxon. Shown are heatmaps of all genes in both the scale-biter and durophage intersection sets at $48 \mathrm{hpf}(\mathbf{A})$ and at $96 \mathrm{hpf}$, $8 \mathrm{dpf}$, and $15 \mathrm{dpf}$ (B). Note how the data fall into four main clusters at each stage that are easily visualized by eye corresponding to genes over or underexpressed in either the scale-biter or durophage respectively. In contrast, genes are not typically differentially expressed in both the scale-biter and durophage taxa. For instance, the plot in $\mathbf{A}$ shows genes overexpressed in the scale-biter, and note that these same genes are similarly expressed among the other three taxa. (PDF $12001 \mathrm{~kb}$ )

Additional file 17: Table S8. Genes in scale-biter intersection set at 48 hpf. This is a comma separated table of the genes in the $48 \mathrm{hpf}$ scalebiter intersection set. Given are edgeR results for each pairwise comparison. Columns indicating whether a gene is included in the intersection set at a threshold of 1.5 or 2 fold are provided. (CSV $143 \mathrm{~kb}$ )

Additional file 18: Table S9. Genes in scale-biter intersection set at 96 hpf. This is a comma separated table of the genes in the $96 \mathrm{hpf}$ scale-biter intersection set. Given are edgeR results for each pairwise comparison. Columns indicating whether a gene is included in the intersection set at a threshold of 1.5 or 2 fold are provided. (CSV $65 \mathrm{~kb}$ )

Additional file 19: Table S10. Genes in scale-biter intersection set at 8 $\mathrm{dpf}$. This is a comma separated table of the genes in the $8 \mathrm{dpf}$ scale-biter intersection set. Given are edgeR results for each pairwise comparison. Columns indicating whether a gene is included in the intersection set at a threshold of 1.5 or 2 fold are provided. (CSV $48 \mathrm{~kb}$ )

Additional file 20: Table S11. Genes in scale-biter intersection set at 15 $\mathrm{dpf}$. This is a comma separated table of the genes in the $15 \mathrm{dpf}$ scale-biter intersection set. Given are edgeR results for each pairwise comparison. Columns indicating whether a gene is included in the intersection set at a threshold of 1.5 or 2 fold are provided. (CSV $91 \mathrm{~kb}$ )

Additional file 21: Table S12 Genes in durophage intersection set at $48 \mathrm{hpf}$. This is a comma separated table of the genes in the $48 \mathrm{hpf}$ durophage intersection set. Given are edgeR results for each pairwise comparison. Columns indicating whether a gene is included in the intersection set at a threshold of 1.5 or 2 fold are provided. (CSV $76 \mathrm{~kb}$ )

Additional file 22: Table S13. Genes in durophage intersection set at $96 \mathrm{hpf}$. This is a comma separated table of the genes in the $96 \mathrm{hpf}$ durophage intersection set. Given are edgeR results for each pairwise comparison. Columns indicating whether a gene is included in the intersection set at a threshold of 1.5 or 2 fold are provided. (CSV $26 \mathrm{~kb}$ )

Additional file 23: Table S14. Genes in durophage intersection set at 8 $\mathrm{dpf}$. This is a comma separated table of the genes in the $8 \mathrm{dpf}$ durophage intersection set. Given are edgeR results for each pairwise comparison. Columns indicating whether a gene is included in the intersection set at a threshold of 1.5 or 2 fold are provided. (CSV $22 \mathrm{~kb}$ )

Additional file 24: Table S15. Genes in durophage intersection set at $15 \mathrm{dpf}$. This is a comma separated table of the genes in the $15 \mathrm{dpf}$ durophage intersection set. Given are edgeR results for each pairwise comparison. Columns indicating whether a gene is included in the intersection set at a threshold of 1.5 or 2 fold are provided. (CSV $13 \mathrm{~kb}$ )
Additional file 25: Table S16. GOstats results for scale-biter intersection set. This is an excel table of providing GOstats overrepresentation enrichment analysis results for each of the 4 scale-biter intersection sets. (XLS $87 \mathrm{~kb}$ )

Additional file 26: Table S17. GOstats results for durophage intersection set. This is an excel table of providing GOstats overrepresentation enrichment analysis results for each of the 4 durophage intersection sets. (XLS $53 \mathrm{~kb}$ )

Additional file 27: Table S18. WebGestalt results for scale-biter intersection set. This is an excel table of providing WebGestalt overrepresentation enrichment analysis results for each of the 4 scale-biter intersection sets. Human symbols were used for analysis and genes without orthology assignment were excluded. (XLS $74 \mathrm{~kb})$

Additional file 28: Table S19. WebGestalt results for durophage intersection set. This is an excel table of providing WebGestalt overrepresentation enrichment analysis results for each of the 4 durophage intersection sets. Human symbols were used for analysis and genes without orthology assignment were excluded. (XLS 66 kb)

Additional file 29: Table S20. DAVID results for scale-biter intersection set. This is an excel table of providing DAVID overrepresentation enrichment analysis results for each of the 4 scale-biter intersection sets. ZFIN ids were used for analysis and genes without orthology assignment were excluded. (XLS $164 \mathrm{~kb}$ )

Additional file 30: Table S21. DAVID results for durophage intersection set. This is an excel table of providing DAVID overrepresentation enrichment analysis results for each of the 4 durophage intersection sets. ZFIN ids were used for analysis and genes without orthology assignment were excluded. (XLS $90 \mathrm{~kb}$ )

Additional file 31: Table S22. edgeR results table for identification of $\mathrm{DE}$ genes. This is a tab delimited table of the results from pair-wise comparisons among taxa at each stage to test for differential expression of genes using edgeR. GLM models were built for each stage and TMM normalization was calculated and applied at each stage. Genes filtered in a given stage are represented by NA. (GZ 10772 kb)

\section{Abbreviations}

cpm: Read counts per million; DE: Differentially expressed; dpf: Days post fertilization; GLM: Generalized linear model; GSEA: Gene set enrichment analysis (as implemented in Broad Institutes GSEA program); hpf: Hours post fertilization; LogFC: Logarithimic (base 2) fold-change; MGI: Mouse Genome Informatics Database; ML: Maximum likelihood; PC: Principal component; PheGenl: NCBI Phenotype-Genotype Integrator; ppt: Parts per thousand (salinity); ZFIN: Zebrafish Model Organism Database

\section{Acknowledgements}

We are indebted to the Gerace Research Centre and its staff on San Salvador Island, Bahamas for logistical support for this research, as well as to the Bahamian Government for letting us work on pupfishes in their wonderful country. Many thanks to Emily Funk, Brian Lazzaro, Steven Bogdanowicz, Jose Andrés, Qi Sun, Casey Dillman, James Lewis, and Linlin Zhang for discussions on experimental design, bioinformatics analysis, and the interpretation of these data. Their comments and critique have greatly improved this project. Thanks to Diane Nacci and her lab at the EPA for providing us with a C. variegatus tissue sample used for sequencing. Finally we thank two anonymous reviewers for their great comments that strengthened this paper. This project was begun in collaboration with Richard G. Harrison and completed after his untimely death. We dedicate this paper to his memory and in honor of his thoughtful contributions to evolutionary biology.

\section{Funding}

Funding for sequencing, assembly, and annotation of the C. variegatus reference genome assembly was provided to $\mathrm{W}$. Warren by a $\mathrm{NIH}$ 2R24OD011198-04A1 grant. Funding for all the rest of the project (including experimental design, RNA-seq sequencing, and RNA-seq analysis) was provided by the Department of Ecology and Evolutionary Biology, Cornell University, a Cornell Center for Vertebrate Genomics Fellowship to E. Lencer, as well as an NSF Dissertation Improvement Grant \#1404367 to E. Lencer. 


\section{Availability of data and materials}

-The $C$. variegatus genome is available at NCBI GenBank, Accession GCA_000732505.1.

-DNA sequences used for genome assemble are available at NCBI SRA, Accessions SRX528039- SRX528041, SRX526471- SRX526477.

-Short read CDNA sequences used for RNA-seq analysis are available at NCBI SRA, SRR2990976-SRR2991005, SRR5575187-SRR5575197, https:// www.ncbi.nlm.nih.gov/bioproject/PRJNA305422.

-Datasets generated during the current study are available as a tab delimited table of edgeR results from the RNA-seq data as Additional file 10. A tab delimited table of RPKM values is available on the Dryad repository, doi:10.5061/dryad.mb3gb.

-A PHYLIP file of DNA alignments used for RAxML is available on the Dryad repository, doi:10.5061/dryad.mb3gb.

-A nexus file of the ML tree reported in this paper is available on the Dryad repository, doi:10.5061/dryad.mb3gb.

-The phylogenetic tree reproduced here from ref. [31] is available on the Dryad repository, DOl:http://dx.doi.org/10.5061/dryad.5k4k4 [50].

\section{Authors' contributions}

EL performed all experimental procedures and analyses of the RNA-seq data and wrote the manuscript. WW sequenced and assembled the $C$. variegatus genome and wrote the genome sequencing sections of the manuscript. RH helped conceive of this project and provided advice and support throughout much of this project. AM helped to conceive of the project, co-wrote manuscript, and provided advice and support throughout this project. All authors read and approved the final manuscript.

\section{Competing interests}

The authors declare that they have no competing interests.

\section{Consent for publication}

\section{Not applicable.}

\section{Ethics approval and consent to participate}

All wild collections, animal husbandry, and procedures were approved by Cornell IACUC, protocol number 2011-0045 to ESL and ARM. Wild fish were collected from San Salvador Island, Bahamas, under Bahamas Environment, Science \& Technology permit issued on November 10, 2012 and Export Permit 23/2013 issued on February 4, 2013.

\section{Publisher's Note}

Springer Nature remains neutral with regard to jurisdictional claims in published maps and institutional affiliations.

\section{Author details}

'Department of Ecology and Evolutionary Biology, Cornell University, Ithaca, NY 14850, USA. ${ }^{2}$ McDonnell Genome Institute, Washington University School of Medicine, St Louis, MO 63108, USA.

Received: 20 January 2017 Accepted: 22 May 2017

Published online: 30 May 2017

\section{References}

1. Averof M, Patel N. Crustacean appendage evolution associated with changes in Hox gene expression. Nature. 1997;388:682-6.

2. Shapiro MD, Marks ME, Peichel CL, Blackman BK, Nereng KS, Jónsson B, et al. Genetic and developmental basis of evolutionary pelvic reduction in threespine sticklebacks. Nature. 2004;428:717-23.

3. Shubin NH, Tabin C, Carroll S. Deep homology and the origins of evolutionary novelty. Nature. 2009:457:818-23.

4. Reed RD, Papa R, Martin A, Hines HM, Counterman BA, Pardo-Diaz C, et al. optix drives the repeated convergent evolution of butterfly wing pattern mimicry. Science. 2011;333:1137-41.

5. Nakamura T, Gehrke AR, Lemberg J, Szymaszek J, Shubin NH. Digits and fin rays share common developmental histories. Nature. 2016;537:225-8.

6. Ferry-Graham LA, Lauder GV. Aquatic prey capture in ray-finned fishes: a century of progress and new directions. J Morphol. 2001;248:99-119.

7. Wainwright PC, Bellwood DR, Westneat MW, Grubich JR, Hoey A. A functional morphospace for the skull of labrid fishes: patterns of diversity in a complex biomechanical system. Biol J Linn Soc. 2004;82:1-25.
8. Liem K. Evolutionary strategies and morphological innovations: cichlid pharyngeal jaws. Syst Biol. 1973;22:425-41.

9. Powder KE, Albertson RC. Developmental biology. Developmental Biology Elsevier. 2016;415:338-46.

10. Hulsey C, Fraser G, Streelman J. Evolution and development of complex biomechanical systems: 300 million years of fish jaws. Zebrafish. 2005;2:243-57.

11. Albertson RC, Streelman JT, Kocher TD, Yelick PC. Integration and evolution of the cichlid mandible: the molecular basis of alternate feeding strategies. Proc Natl Acad Sci U S A. 2005;102:16287-92.

12. Martin $\mathrm{CH}$, Wainwright PC. A remarkable species flock of Cyprinodon pupfishes endemic to San Salvador Island, Bahamas. Bulletin of the Peabody Museum of Natural History. 2013;54:231-40.

13. Lencer ES, Riccio ML, McCune AR. Changes in growth rates of oral jaw elements produce evolutionary novelty in bahamian pupfish. J Morphol. 2016;277:935-47.

14. Noden DM. The role of the neural crest in patterning of avian cranial skeletal, connective, and muscle tissues. Dev Biol. 1983;96:144-65.

15. Hu D, Marcucio RS, Helms JA. A zone of frontonasal ectoderm regulates patterning and growth in the face. Development. 2003;130:1749-58.

16. Wada N, Javidan Y, Nelson S, Carney T, Kelsh RN, Schilling TF. Hedgehog signaling is required for cranial neural crest morphogenesis and chondrogenesis at the midline in the zebrafish skull. Development and disease. 2005;132:3977-88.

17. Szabo-Rogers HL, Smithers LE, Yakob W, Liu KJ. New directions in craniofacial morphogenesis. Dev Biol. 2010;341:84-94. Elsevier Inc

18. Kuratani S. Craniofacial development and the evolution of the vertebrates: the old problems on a new background. Zool Sci. 2005;22:1-19.

19. Mallarino R, Campas O, Fritz JA, Burns KJ, Weeks OG, Brenner MP, et al. Closely related bird species demonstrate flexibility between beak morphology and underlying developmental programs. Proc Natl Acad Sci. 2012;109:16222-7.

20. Abzhanov A, Protas M, Grant BR, Grant PR, Tabin CJ. Bmp4 and morphological variation of beaks in Darwin's finches. Science. 2004;305:1462-5.

21. Abzhanov A, Kuo WP, Hartmann C, Grant BR, Grant PR, Tabin CJ. The calmodulin pathway and evolution of elongated beak morphology in Darwin's finches. Nature. 2006;442:563-7.

22. Parsons K, Albertson R. Roles for Bmp4 and CaM1 in Shaping the jaw: Evo-Devo and beyond. Annu Rev Genet. 2009;43:369-88.

23. Heisenberg CP, Brand M, Jiang YJ, Warga RM, Beuchle D, van Eeden FJ, et al. Genes involved in forebrain development in the zebrafish, Danio rerio. Development. 1996;123:191-203.

24. Eberhart JK, Swartz ME, Crump JG, Kimmel CB. Early hedgehog signaling from neural to oral epithelium organizes anterior craniofacial development. Development. 2006;133:1069-77.

25. Brugmann $S A$, Goodnough $L H$, Gregorieff $A$, Leucht $P$, Berge ten $D$, Fuerer $C$, et al. Wnt signaling mediates regional specification in the vertebrate face. Development. 2007;134:3283-95.

26. Parsons K, Taylor AT, Powder KE, Albertson RC. Wnt signalling underlies the evolution of new phenotypes and craniofacial variability in Lake Malawi cichlids. Nat Commun. 2014:5:1-11.

27. Bhullar B-AS, Morris ZS, Sefton EM, Tok A, Tokita M, Namkoong B, et al. A molecular mechanism for the origin of a key evolutionary innovation, the bird beak and palate, revealed by an integrative approach to major transitions in vertebrate history. Evolution. 2015;69:1665-77.

28. Fish JL, Sklar RS, Woronowicz KC, Schneider RA. Multiple developmental mechanisms regulate species-specific jaw size. Development. 2014;141:674-84.

29. Brugmann SA, Powder KE, Young NM, Goodnough LH, Hahn SM, James AW, et al. Comparative gene expression analysis of avian embryonic facial structures reveals new candidates for human craniofacial disorders. Hum Mol Genet. 2010;19:920-30.

30. Martin $\mathrm{CH}$, Wainwright PC. Trophic novelty is linked to exceptional rates of morphological diversification in two adaptive radiations of Cyprinodon pupfish. Evolution. 2011;65:2197-212.

31. Martin $\mathrm{CH}$, Feinstein LC. Novel trophic niches drive variable progress towards ecological speciation within an adaptive radiation of pupfishes. Mol Ecol. 2014;23:1846-62.

32. D'Arcy T. On growth and form. Cambridge: University Press; 1942.

33. Alberch P, Gould SJ, Oster GF, Wake DB. Size and shape in ontogeny and phylogeny. Paleobiology. 1979;5:296-317. 
34. Holtmeier C. Heterochrony, maternal effects, and phenotypic variation among sympatric pupfishes. Evolution. 2001;55:330-8.

35. Turner BJ, Duvernell DD, Bunt T, Barton M. Reproductive isolation among endemic pupfishes (Cyprinodon) on San Salvador Island, Bahamas: microsatellite evidence. Biol J Linn Soc. 2008;95:566-82.

36. Martin $\mathrm{CH}$. Context dependence in complex adaptive landscapes: frequency and trait-dependent selection surfaces within an adaptive radiation of Caribbean pupfishes. Evolution. 2016;70:1265-82.

37. Finne K. Phylogeographic structure of the Atlantic pupfish, Cyprinodon variegatus (Cyprinodontidae), along the eastern coast of North America: Evidence from mitochondrial nucleotide sequences. Blacksburg: Virginia Polytechnic Institute and State University; 2001. http://hdl.handle.net/10919/ 31782.

38. Haney RA, Turner BJ, Rand DM. A cryptic lineage within the pupfish Cyprinodon dearborni suggests multiple colonizations of South America. J Fish Biol. 2009;75:1108-14.

39. Martin $\mathrm{CH}$. The cryptic origins of evolutionary novelty: 1000-fold faster trophic diversification rates without increased ecological opportunity or hybrid swarm. Evolution. 2016;70:2504-19.

40. Gnerre S, MacCallum I, Przybylski D, Ribeiro FJ, Burton JN, Walker BJ, et al. High-quality draft assemblies of mammalian genomes from massively parallel sequence data. Proc Natl Acad Sci USA National Acad Sciences. 2011;108:1513-8.

41. Iwamatsu T. Stages of normal development in the medaka Oryzias latipes. Mech Dev. 2004;121:605-18.

42. Bolger AM, Lohse M, Usadel B. Trimmomatic: a flexible trimmer for Illumina sequence data. Bioinformatics. 2014;30(15):2114-20.

43. Dobin A, Davis CA, Schlesinger F, Drenkow J, Zaleski C, Jha S, et al. STAR: ultrafast universal RNA-seq aligner. Bioinformatics. 2013;29:15-21.

44. Subramanian A, Tamayo P, Mootha V, Mukherjee S, Ebert B, Gillette M, et al. Gene set enrichment analysis: a knowledge-based approach for interpreting genome-wide expression profiles. Proc Natl Acad Sci. 2005;102:15545-50.

45. Falcon S, Gentleman R. Using GOstats to test gene lists for GO term association. Bioinformatics. 2007;23:257-8.

46. Zhang B, Kirov S, Snoddy J. WebGestalt: an integrated system for exploring gene sets in various biological contexts. Nucleic Acids Res. 2005;33:W741-8.

47. Huang DW, Sherman BT, Lempicki RA. Systematic and integrative analysis of large gene lists using DAVID bioinformatics resources. Nat Protoc. 2008;4:44-57.

48. Huang DW, Sherman BT, Lempicki RA. Bioinformatics enrichment tools: paths toward the comprehensive functional analysis of large gene lists. Nucleic Acids Res. 2009:37:1-13.

49. Frandsen PB, Calcott B, Christoph M, Lanfear R. Automatic selection of partitioning schemes for phylogenetic analyses using iterative k-means clustering of site rates. BMC Evol Biol. 2015;15:13.

50. Martin $\mathrm{CH}$, Feinstein LC. Data from: Novel trophic niches drive variable progress toward ecological speciation within an adaptive radiation of pupfishes. Dryad Digital Repository. 2014. http://dx.doi.org/10.5061/dryad. $5 k 4 k 4$.

51. Heisenberg CP, Tada M, Rauch G, Saúde L. SilberblickWnt11 mediates convergent extension movements during zebrafish gastrulation. Nature. 2000;405:76-81.

52. Cappellen D, Luong-Nguyen N-H, Bongiovanni S, Grenet O, Wanke C, Susa M. Transcriptional program of mouse Osteoclast differentiation governed by the macrophage Colony-stimulating factor and the Ligand for the receptor activator of NFkappa B. J Biol Chem. 2002;277:21971-82.

53. Väänänen HK, Laitala-Leinonen T. Osteoclast lineage and function. Arch Biochem Biophys. 2008;473:132-8.

54. Bilezikian J, Raisz L, Martin TJ, editors. Principles of bone biology. 3rd ed. Amsterdam; London: Elsevier; 2016.

55. Parry DA, Poulter JA, Logan CV, Brookes SJ, Jafri H, Ferguson $\mathrm{CH}$, et al. Identification of mutations in SLC24A4, encoding a potassium-dependent sodium/calcium exchanger, as a cause of Amelogenesis Imperfecta. Am J Hum Genet. 2013;92:307-12.

56. Abouzeid H, Boisset G, Favez T, Youssef M, Marzouk I, Shakankiny N, et al. Mutations in the SPARC-related modular calcium-binding protein 1 Gene, SMOC1, cause Waardenburg Anophthalmia syndrome. Am J Hum Genet. 2011;88:92-8.

57. Rainger J, van Beusekom E, Ramsay JK, McKie L, Al-Gazali L, Pallotta R, et al. Loss of the BMP antagonist, SMOC-1, causes Ophthalmo-Acromelic (Waardenburg Anophthalmia) syndrome in humans and mice. PLoS Genet. 2011;7:e1002114. Wilkie AOM, editor
58. Powder KE, Cousin H, McLinden GP, Albertson RC. A nonsynonymous mutation in the transcriptional regulator lbh is associated with cichlid craniofacial adaptation and neural crest cell development. Mol Biol Evol. 2014;31:3113-24.

59. Miller CT, Schilling TF, Lee K, Parker J, Kimmel CB. Sucker encodes a zebrafish Endothelin-1 required for ventral pharyngeal arch development. Development. 2000;127:3815-28.

60. Shin M, Levorse J, Tilghman R, Tilghman S. The temporal requirement for endothelin receptor-B signalling during neural crest development. Nature. 1999;402:496-501.

61. Mantila Roosa SM, Liu Y, Turner CH. Gene expression patterns in bone following mechanical loading. J Bone Miner Res. 2010;26:100-12.

62. Mallarino R, Grant PR, Grant BR, Herrel A, Kuo WP, Abzhanov A. Two developmental modules establish 3D beak-shape variation in Darwin's finches. Proc Natl Acad Sci U S A. 2011;108:4057-62.

63. Young NM, Chong HJ, Hu D, Hallgrimsson B, Marcucio RS. Quantitative analyses link modulation of sonic hedgehog signaling to continuous variation in facial growth and shape. Development. 2010;137:3405-9.

64. Albertson RC, Kocher TD. Genetic and developmental basis of cichlid trophic diversity. Heredity. 2006;97:211-21.

65. Wu P. Molecular Shaping of the beak. Science. 2004;305:1465-6.

66. Piotrowski T, Schilling TF, Brand M, Jiang Y-J, Heisenberg C-P, Beuchle D, et al. Jaw and branchial arch mutants in zebrafish II: anterior arches and cartilage differentiation. Development. 1996;123:345-56.

67. Schilling TF, Piotrowski T, Grandel H, Brand M, Heisenberg C-P, Jiang Y-J, et al. Jaw and branchial arch mutants in zebrafish I: branchial arches. Development. 1996;123:329-44.

68. Clouthier DE, Hosoda K, Richardson JA, Williams SC, Yanagisawa H, Kuwaki T, et al. Cranial and cardiac neural crest defects in endothelin-a receptordeficient mice. Development. 1998;125:813-24.

69. Kempf H, Linares C, Corvol P, Gasc JM. Pharmacological inactivation of the endothelin type a receptor in the early chick embryo: a model of mispatterning of the branchial arch derivatives. Development. 1998;125:4931-41.

70. Kimmel CB, Miller CT, Moens CB. Specification and morphogenesis of the Zebrafish larval head skeleton. Dev Biol. 2001;233:239-57.

71. Khaitovich P, Weiss G, Lachmann M, Hellmann I, Enard W, Muetzel B, et al. A neutral model of Transcriptome evolution. PLoS Biol. 2004:2:e132.

72. Brawand D, Soumillon M, Necsulea A, Julien P, Csárdi G, Harrigan P, et al. The evolution of gene expression levels in mammalian organs. Nature. 2011;478:343-8.

73. Coolon JD, Mcmanus CJ, Stevenson KR, Graveley BR, Wittkopp PJ. Tempo and mode of regulatory evolution in drosophila. Genome Res. 2014;24:797-808.

74. Gunter HM, Fan S, Xiong F, Franchini P, Fruciano C, Meyer A. Shaping development through mechanical strain: the transcriptional basis of dietinduced phenotypic plasticity in a cichlid fish. Mol Ecol. 2013;22:4516-31.

75. Sanger TJ, Seav SM, Tokita M, Langerhans RB, Ross LM, Losos JB, et al. The oestrogen pathway underlies the evolution of exaggerated male cranial shapes in Anolis lizards. Proc R Soc B Biol Sci. 2014;281:20140329.

76. Krishnan V, Bryant H, MacDougald O. Regulation of bone mass by Wnt signaling. J Clin Investig. 2006;116:1202-9.

77. Reid BS, Yang H, Melvin VS, Taketo MM, Williams T. Ectodermal WNT/Betacatenin signaling shapes the mouse face. Dev Biol. 2011;349:261-9.

78. Musso G, Tasan M, Mosimann C, Beaver JE, Plovie E, Carr LA, et al. Novel cardiovascular gene functions revealed via systematic phenotype prediction in zebrafish. Development. 2013;141:224-35.

79. Powder KE, Milch K, Asselin G, Albertson RC. Constraint and diversification of developmental trajectories in cichlid facial morphologies. EvoDevo. 2015;6:1-14.

80. Hu D, Marcucio RS. Unique organization of the frontonasal ectodermal zone in birds and mammals. Dev Biol. 2009;325:200-10.

81. Duan C, Ren H, Gao S. Insulin-like growth factors (IGFs), IGF receptors, and IGF-binding proteins: roles in skeletal muscle growth and differentiation. Gen Comp Endocrinol. 2010;167:344-51.

82. Sutter NB, Bustamante CD, Chase K, Gray MM, Zhao K, Zhu L, et al. A single IGF1 allele is a major determinant of small size in dogs. Science. 2007:316:112-5.

83. Ferguson MW, Sharpe PM, Thomas BL. Differential expression of insulin-like growth factors I and II (IGF I and II), mRNA, peptide and binding protein 1 during mouse palate development: comparison with TGFbeta peptide distribution. J Anat. 1992;181:129-238.

84. Fujita K, Taya Y, Shimazu Y, Aoba T, Soeno Y. Molecular signaling at the fusion stage of the mouse mandibular arch: involvement of insulin-like growth factor family. Int J Dev Biol. 2013;57:399-406. 
85. Eckstein F, Pavicic T, Nedbal S, Schmidt C, Wehr U, Rambeck W, et al. Insulin-like growth factor-binding protein-2 (IGFBP-2) overexpression negatively regulates bone size and mass, but not density, in the absence and presence of growth hormone/IGF-l excess in transgenic mice. Anat Embryol. 2002;206:139-48.

86. Fisher MC, Meyer C, Garber G, Dealy CN. Role of IGFBP2, IGF-I and IGF-II in regulating long bone growth. Bone. 2005;37:741-50.

87. Hamidouche Z, Fromigué O, Ringe J, Häupl T, Marie PJ. Crosstalks between integrin alpha 5 and IGF2/IGFBP2 signalling trigger human bone marrow-derived mesenchymal stromal osteogenic differentiation. BMC Cell Biol. 2010;11:44.

88. Takayanagi H. Osteoimmunology: shared mechanisms and crosstalk between the immune and bone systems. Nat Rev Immunol. 2007;7:292-304.

89. Theill LE, Boyle WJ, Penninger JM. RANK-L and RANK: T cells, bone loss, and mammalian evolution. Annu Rev Immunol. 2002;20:795-823.

90. Xing W, Baylink D, Kesavan C, Hu Y, Kapoor S, Chadwick RB, et al. Global gene expression analysis in the bones reveals involvement of several novel genes and pathways in mediating an anabolic response of mechanical loading in mice. J Cell Biochem. 2005;96:1049-60.

91. Sontam DM, Firth EC, Tsai P, Vickers MH, O'Sullivan JM. Different exercise modalities have distinct effects on the integrin-linked kinase (ILK) and ca 2+signaling pathways in the male rat bone. Physiological Reports. 2015;3:e12568.

92. West RJD, Kodric-Brown A. Mate choice by both sexes maintains reproductive isolation in a species flock of pupfish (Cyprinodon spp) in the Bahamas. Ethology. 2015;121:793-800.

93. Kodric-Brown A, West RJD. Asymmetries in premating isolating mechanisms in a sympatric species flock of pupfish (Cyprinodon). Behav Ecol. 2013;25:69-75.

94. Parichy D. Evolution of danio pigment pattern development. Heredity. 2006;97:200-10.

95. Roberts RB, Hu Y, Albertson RC, Kocher TD. Craniofacial divergence and ongoing adaptation via the hedgehog pathway. Proc Natl Acad Sci. 2011;108:13194-9.

96. Robinson MC, Davis RL. San Salvador Island GIS Database. University of New Haven \& Bahamian Field Station; 1999. Available from: http//www.newhaven.edu/

\section{Submit your next manuscript to BioMed Central and we will help you at every step:}

- We accept pre-submission inquiries

- Our selector tool helps you to find the most relevant journal

- We provide round the clock customer support

- Convenient online submission

- Thorough peer review

- Inclusion in PubMed and all major indexing services

- Maximum visibility for your research

Submit your manuscript at www.biomedcentral.com/submit

) Biomed Central 